Progress In Oceanography

June 2015, Volume 135 Pages 18-36

http://dx.doi.org/10.1016/j.pocean.2015.03.009

http://archimer.ifremer.fr/doc/00268/37968/

(c) 2015 Elsevier Ltd. All rights reserved.

\title{
Structure, transports and transformations of the water masses in the Atlantic Subpolar Gyre
}

\author{
Garcia-lbanez Maribel I. ${ }^{1,{ }^{*}}$, Pardo Paula C. ${ }^{1}$, Carracedo Lidia ${ }^{1}$, Mercier Herlé ${ }^{2}$, Lherminier Pascale ${ }^{3}$, \\ Rios Aida F. ${ }^{1}$, Pérez Fiz F. ${ }^{1}$ \\ ${ }^{1}$ CSIC, Inst Invest Marinas, Vigo 36208, Spain. \\ 2 Ifremer Ctr Brest, CNRS, Lab Phys Oceans, UMR CNRS Ifremer IRD UBO 6523, Plouzane, France. \\ ${ }^{3}$ Ifremer, Lab Phys Oceans, UMR CNRS Ifremer IRD UBO 6523, Plouzane, France.
}

* Corresponding author : Maribel I. Garcia-Ibanez, email address : maribelgarcia@iim.csic.es ; pconde@iim.csic.es ; Icarracedo@iim.csic.es ; Herle.Mercier@ifremer.fr ;

Pascale.Lherminier@ifremer.fr ; aida@iim.csic.es ; fiz.perez@iim.csic.es

\begin{abstract}
:
We discuss the distributions and transports of the main water masses in the North Atlantic Subpolar Gyre (NASPG) for the mean of the period 2002-2010 (OVIDE sections 2002-2010 every other year), as well as the inter-annual variability of the water mass structure from 1997 (4x and METEOR sections) to 2010. The water mass structure of the NASPG, quantitatively assessed by means of an Optimum MultiParameter analysis (with 14 water masses), was combined with the velocity fields resulting from previous studies using inverse models to obtain the water mass volume transports. We also evaluate the relative contribution to the Atlantic Meridional Overturning Circulation (AMOC) of the main water masses characterizing the NASPG, identifying the water masses that contribute to the AMOC variability. The reduction of the magnitude of the upper limb of the AMOC between 1997 and the 2000s is associated with the reduction in the northward transport of the Central Waters. This reduction of the northward flow of the AMOC is partially compensated by the reduction of the southward flow of the lower limb of the AMOC, associated with the decrease in the transports of Polar Intermediate Water and Subpolar Mode Water (SPMW) in the Irminger Basin. We also decompose the flow over the Reykjanes Ridge from the East North Atlantic Basin to the Irminger Basin (9.4 $\pm 4.7 \mathrm{~Sv})$ into the contributions of the Central Waters $(2.1 \pm 1.8 \mathrm{~Sv}$ ), Labrador Sea Water (LSW, $2.4 \pm 2.0 \mathrm{~Sv}$ ), Subarctic Intermediate Water (SAIW, $4.0 \pm 0.5 \mathrm{~Sv}$ ) and Iceland-Scotland Overflow Water (ISOW, $0.9 \pm 0.9 \mathrm{~Sv}$ ). Once LSW and ISOW cross over the Reykjanes Ridge, favoured by the strong mixing around it, they leave the Irminger Basin through the deep-to-bottom levels. The results also give insights into the water mass transformations within the NASPG, such as the contribution of the Central Waters and SAIW to the formation of the different varieties of SPMW due to air-sea interaction.
\end{abstract}




\section{Highlights}

- We discuss the 1997-2010 water mass structure and transport of the WOCE A25 line. We combine OMP analysis with velocity fields. The Central Waters transport reduction is linked to the AMOC decline. The weakening of intermediate water transports partially balances the AMOC decline. -Water masses exchanges across the Reykjanes Ridge were also evaluated.

\section{List of acronyms}

$\begin{array}{ll}\text { AMOC } & \text { Atlantic Meridional Overturning Circulation } \\ \text { CGFZ } & \text { Charlie-Gibbs Fracture Zone } \\ \text { CTD } & \text { Conductivity-Temperature-Depth } \\ \text { DSOW } & \text { Denmark Strait Overflow Water } \\ \text { ENA } & \text { East North Atlantic (Basin) } \\ \text { ENACW } & \text { East North Atlantic Central Water } \\ \text { ISOW } & \text { Iceland-Scotland Overflow Water } \\ \text { LSW } & \text { Labrador Sea Water } \\ \text { MW } & \text { Mediterranean Water } \\ \text { NAC } & \text { North Atlantic Current } \\ \text { NADW } & \text { North Atlantic Deep Water } \\ \text { NAO } & \text { North Atlantic Oscillation } \\ \text { NASPG } & \text { North Atlantic Subpolar Gyre } \\ \text { NEADW } & \text { North East Atlantic Deep Water, upper (NEADW } \text { ) and lower (NEADW L) } \\ \text { OMP } & \text { Optimum MultiParameter, classical (cOMP) and extended (eOMP) } \\ \text { OVIDE } & \text { Observatoire de la variabilité interannuelle et décennale en Atlantique Nord } \\ \text { PIW } & \text { Polar Intermediate Water } \\ \text { SAIW } & \text { Subarctic Intermediate Water } \\ \text { SPMW } & \text { Subpolar Mode Water, in the Iceland (IcSPMW) and Irminger (IrSPMW) Basins } \\ \text { SWT } & \text { Source Water Type } \\ \text { WOCE } & \text { World Ocean Circulation Experiment } \\ \end{array}$




\section{Introduction}

The North Atlantic Subpolar Gyre (NASPG) is one of the key regions of the global ocean circulation, where interactions with the atmosphere contribute to warm-to-cold water mass transformations (e.g., Bersch et al., 2007; Yashayaev et al., 2007; Sarafanov, 2009; Sarafanov et al., 2012). The North Atlantic Current (NAC) carries warm and salty waters from the subtropics towards the north-eastern Atlantic Ocean (Fig. 1). East of the Charlie-Gibbs Fracture Zone (CGFZ) the NAC bifurcates into two branches, one flowing towards the Nordic Seas, and the other flowing towards the Iceland Basin (Read, 2000), where the Subpolar Mode Water (SPMW) is formed (McCartney and Talley, 1982; Tsuchiya et al., 1992; van Aken and Becker, 1996; Brambilla and Talley, 2008). The densest variety of SPMW is formed in the Labrador Sea (McCartney and Talley, 1982; Yashayaev, 2007), where intense winter heat loss leads to deep convection and formation of the Labrador Sea Water (LSW) (Tsuchiya et al., 1992; Bersch et al., 2007; Yashayaev, 2007). Afterwards, LSW joins the Deep Western Boundary Current (Bersch et al., 2007), where it flows over the Denmark Strait Overflow Water (DSOW) and the Iceland-Scotland Overflow Water (ISOW) (both derived from waters from the Arctic Ocean and the Nordic Seas; Rudels et al., 2002; Tanhua et al., 2008) and these altogether constitute the North Atlantic Deep Water (NADW; Dickson and Brown, 1994).

The processes of water mass formation in the Subpolar North Atlantic, the Arctic Ocean and the Nordic Seas affect the Atlantic Meridional Overturning Circulation (AMOC) on long timescales (Böning et al., 1996; Willebrand et al., 2001; Marsh et al., 2005; Josey et al., 2009). The AMOC transports heat and anthropogenic carbon from the southern hemisphere of the Atlantic Ocean to the subtropics and the high northern latitudes, playing an active role in the climate variability. The North Atlantic Oscillation (NAO) is the dominant mode of the atmospheric variability in the NASPG (Hurrell, 1995), which influences both its strength and circulation (Curry and McCartney, 2001; Häkkinen and Rhines, 2004) and its shape (Bersch, 2002). Both direct observations (Flatau et al., 2003; Häkkinen and Rhines, 2004) and model results (Böning et al., 2006) confirm a spin down of the circulation of the NASPG between the mid-1990s and the 2000s due to the shift from high to low NAO indices, based on high-frequency time series. The NAO also influences the AMOC strength (e.g., Eden and Willebrand, 2001; Marsh et al., 2005; Böning et al., 
103 2006; Balmaseda et al., 2007), which has decreased over the last decade (Balmaseda et al., 2007;

104 Desbruyères et al., 2013; Xu et al., 2013; Mercier et al., 2015) and resulted in reductions in the 105 poleward heat transport (Bryden et al., 2014; Mercier et al., 2015) and in the uptake of atmospheric 106 carbon dioxide (Pérez et al., 2013).

107 The main objective of this paper is to discuss the distributions and transports of the main 108 water masses in the North Atlantic region for the first decade of the 2000s. We also evaluate the 109 inter-annual variability of the water mass structure from 1997 to 2010 . In the present work we use 110 data from six repeats of the WOCE (World Ocean Circulation Experiment) A25 hydrographic 111 section located at the southern boundary of the NASPG (Fig. 1; Table 1). The data include the $4 x$ 112 section taken in 1997 and the five repeats of the OVIDE (Observatoire de la variabilité 113 interannuelle et décennale en Atlantique Nord) section taken every other year from 2002 to 2010.

114 We obtained the distributions of the main water masses in each section by using an Optimum 115 MultiParameter (OMP) analysis (Thompson and Edwards, 1981; Tomczak, 1981; Mackas et al., 116 1987; Tomczak and Large, 1989) and then we combined them with the velocity fields (from inverse 117 models previously implemented (Lherminier et al., 2007, 2010; Gourcuff et al., 2011; Mercier et al., 118 2015)) in order to estimate the transport of each water mass across the sections. Although this 119 methodology has been applied before (Álvarez et al., 2004; Carracedo et al., 2014), this is the first 120 time that it has been used to evaluate the inter-annual variability of the water mass distributions, 121 specifically from 1997 to 2010 . In addition, we also investigate the water mass contributions to the $122 \mathrm{AMOC}$ and the water mass transformations that take place in the NASPG.

123 The present manuscript is organized as follows. In Section 2 we describe: the cruise data; 124 the methodology followed in the OMP analysis, including a description of the 14 water masses 125 considered; the velocity field obtained from earlier studies; and the methodology used to combine 126 the velocity fields with the water mass distributions. The water mass distributions for the OVIDE 127 period (2002-2010) are described and discussed in Section 3. In Section 4 we describe and 128 discuss the inter-annual variability of the water mass structure from 1997 to 2010 . The water mass 129 volume transports are described and discussed in Section 5 together with an estimation of the 130 circulation and transformation of the water masses in the Subpolar North Atlantic as well as of the 
131 budget of water mass volume transports across the Reykjanes Ridge. We conclude the manuscript 132 in Section 6.

\section{2. Data and methods}

\section{2.1. Biogeochemical data}

The $4 \mathrm{x}$ and OVIDE sections were conducted across the southern boundary of the NASPG from the Iberian Peninsula to Cape Farewell (South Greenland), during the spring-summer periods of 1997 (4x section), 2002, 2004, 2006, 2008 and 2010 (OVIDE sections) (Fig. 1; Table 1). Cruise data is available on the CCHDO (CLIVAR \& Carbon Hydrographic Data Office) webpage

139 (http://cchdo.ucsd.edu). These cruises are suitable for examining the inter-annual to decadal water 140 mass variability because they were carried out at approximately the same time of the year -from

141 June to August- and, except for the near-surface layers, the seasonal differences are expected to 142 be smaller than the inter-annual changes. In addition, the monthly variability of the AMOC is 143 weaker between June and August (Mercier et al., 2015).

144 During the cruises, the temperature and salinity (S) were continuously recorded at each 145 station by using a Conductivity-Temperature-Depth (CTD) instrument. In the cruises prior to 2008 146 a Neil Brown Mark III CTD probe was used, while in the subsequent cruises a Sea-bird Electronics 147911 plus CTD probe was used. To calibrate the conductivity sensor, seawater S samples were 148 analysed on board via a Guildline 8400A salinometer calibrated with IAPSO Standard Seawater 149 following the WOCE standards (Culberson, 1991). The pressure sensor was calibrated in a 150 metrology laboratory using 3 cycles of increasing-decreasing pressure between 0 and $6000 \mathrm{dbar}$.

151 The static and dynamic effects of temperature on the pressure sensor were also estimated and 152 corrected (Branellec and Thierry, 2013). Overall, the CTD measurement accuracies were $1 \mathrm{dbar}$ 153 for pressure, $0.002^{\circ} \mathrm{C}$ for temperature and 0.003 for $\mathrm{S}$. Seawater samples for nutrients (nitrate $\left(\mathrm{NO}_{3}\right)$, phosphate $\left(\mathrm{PO}_{4}\right)$ and silicate $\left(\mathrm{SiO}_{2}\right)$ ) and oxygen $\left(\mathrm{O}_{2}\right)$ were also taken and analysed on board. The nutrients were analysed using an SOC

156 Chemlab AAll type Auto-Analyser coupled with a Digital-Analysis Microstream data capture and a 157 reduction system, following the classic protocols and methods described by Aminot and 
158 Chaussepied (1983). The precision for $\mathrm{NO}_{3}, \mathrm{PO}_{4}$ and $\mathrm{SiO}_{2}$ was evaluated at $0.2,0.02$ and $0.1 \mu \mathrm{mol}$ $159 \mathrm{~kg}^{-1}$, respectively. The $\mathrm{O}_{2}$ was determined by Winkler potentiometric titration following the WOCE 160 standards (Culberson, 1991), with a precision better than $\mu \mathrm{mol} \mathrm{kg}^{-1}$.

161 For further reference, the vertical sections of the mean properties (potential temperature $162(\theta), \mathrm{S}, \mathrm{O}_{2}, \mathrm{NO}_{3}, \mathrm{SiO}_{2}$ and $\left.\mathrm{PO}_{4}\right)$ are shown in Fig. 2.

163

\subsection{Optimum MultiParameter (OMP) analysis}

An Optimum MultiParameter (OMP) analysis (Thompson and Edwards, 1981; Tomczak, 1981; Mackas et al., 1987; Tomczak and Large, 1989) was used to resolve the water mass structure along the sections. The water masses are described by the so-called Source Water Types (SWT), which are points in the $n$-dimensional parameter space ( $n$ is the number of properties that characterize SWTs) (Tomczak, 1999). In this work, the SWTs are characterized by $\theta, \mathrm{S}, \mathrm{O}_{2}^{0}, \mathrm{NO}_{3}^{0}, \mathrm{PO}_{4}^{0}$ and $\mathrm{SiO}_{2}^{0}$ (where the superscript 0 means preformed variables) (Table 2). Given a number of SWTs, the goal of an OMP analysis is to find the fractions of each SWT $\left(\mathrm{X}_{\mathrm{i}}\right)$ in each water sample. The $\mathrm{X}_{\mathrm{i}} \mathrm{s}$ strongly depend on the characterization of the SWTs (Tomczak, 1981), the choice of which is a key step of the analysis. In the following subsection we describe the SWTs included in the analysis and their properties.

\subsubsection{Water mass characterization}

The Subpolar North Atlantic is a region with a large variety of water masses. We considered 14 SWTs as the main water masses explaining the physicochemical variability of this area and which encompass all the water samples of the sections (Fig. 3a, b).

The saltiest waters of the sections are influenced by the Mediterranean Water (MW), which enters the North Atlantic from the Mediterranean Sea. MW is detected as a maximum in S (> 36.1) and $\theta\left(9-11^{\circ} \mathrm{C}\right)$ between 600 and $1700 \mathrm{~m}$ depth in the eastern North Atlantic (Harvey, 1982; Tsuchiya et al., 1992; van Aken and Becker, 1996; Álvarez et al., 2004). Following Castro et al. (1998) and Álvarez et al. (2004), we used the $\theta / S$ properties of MW reported by Wüst and Defant (1936) near Cape St. Vicente (Fig. 3a; Table 2). In this way we avoid solving the mixing processes 
184 between the Mediterranean Outflow Water (overflowing from the Mediterranean Sea) and the 185 central and intermediate waters of the East North Atlantic, which lead to the formation of MW 186 (Ambar and Howe, 1979; Baringer and Price, 1997).

The warmer waters are influenced by the North Atlantic Central Waters (Iselin, 1936). East

188 of the Mid-Atlantic Ridge in the North Atlantic, the predominant variety of these waters is the East 189 North Atlantic Central Water (ENACW) (Harvey, 1982; Pollard et al., 1996; Read, 2000), which is 190 formed by winter convection in the intergyre region (Pollard et al., 1996). The $\theta / S$ characteristics of 191 ENACW can be fitted to a straight line from 12 to $16^{\circ} \mathrm{C}$ (Pollard et al., 1996). The end points from 192 this line are defined by: ENACW ${ }_{16}$, whose $\theta / S$ characteristics match those from the warmer central 193 waters of Pollard et al. (1996); and ENACW ${ }_{12}$, which represents the upper limit of ENACW defined 194 by Harvey (1982) (Fig. 3a; Table 2). Here, we considered these two SWTs together as the Central 195 Waters.

196 Part of the Central Waters carried by the NAC recirculates in the West European Basin 197 (Fig. 1), and part of them spreads towards the Iceland Basin, leading to the formation of SPMW 198 (McCartney and Talley, 1982; Tsuchiya et al., 1992; van Aken and Becker, 1996; Brambilla and 199 Talley, 2008). The hydrographic properties of SPMW change due to air-sea interaction processes 200 (McCartney and Talley, 1982; Brambilla and Talley, 2008). Since this variability cannot be 201 accounted by the OMP analysis, we defined three SWTs to characterize SPMW: two 202 corresponding to SPMW present in the Iceland Basin $\left(\mathrm{SPMW}_{8}\right.$ and SPMW $\left.{ }_{7}\right)$, and another one that 203 accounts for the variety found in the Irminger Basin (IrSPMW, sometimes denoted as Irminger Sea 204 Water (Krauss, 1995)). SPMW 8 and $\mathrm{SPMW}_{7}$ were selected to characterize the thermohaline range 205 of SPMW in the Iceland Basin (6-9 ${ }^{\circ} \mathrm{C}$ and 35.1-35.25) (Stoll et al., 1996; van Aken and Becker, 206 1996) and are going to be considered together as IcSPMW. The $\theta /$ S properties of SPMW 7 (Fig. 3a; 207 Table 2) were chosen close to the mean properties of SPMW over the eastern flank of the 208 Reykjanes Ridge found by Thierry et al. (2008) in a box including the OVIDE section, while the $\theta / S$ 209 properties of $\mathrm{SPMW}_{8}$ correspond to the SPMW variety formed within the Iceland Basin (Brambilla

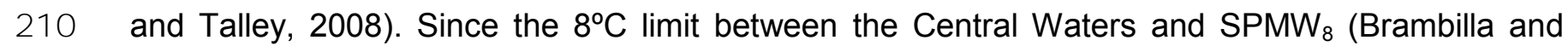
211 Talley, 2008; Brambilla et al., 2008) cannot be directly obtained by the OMP analysis, we 212 constrained the OMP by not allowing the presence of Central Waters east of the western branch of 
213 the NAC (Fig. 1). In the northern part of the Irminger Basin, SPMW is characterized by $\theta$ and S

214 usually lower than $7^{\circ} \mathrm{C}$ and 35.1 , respectively (Thierry et al., 2008). To characterize the SWT for 215 IrSPMW, we chose its $\theta / S$ properties close to those of the Irminger Sea Water described by Krauss 216 (1995) (Fig. 3a; Table 2). These properties were also found by Brambilla and Talley (2008) in the 217 NW Irminger Basin, which could indicate that this is the region of formation of IrSPMW.

218 Once SPMW reaches the Labrador Sea, it is involved in deep convection processes which 219 lead to the formation of LSW (Talley and McCartney, 1982). These episodes of deep convection 220 are forced by the extreme winter heat loss combined with the cyclonic circulation in the Labrador 221 Sea (Lazier et al., 2002). LSW is traceable by its low potential vorticity, relatively low S and high $\mathrm{O}_{2}$ 222 content (Fig. 2) (Talley and McCartney, 1982; Harvey and Arhan, 1988; Pickart, 1992; Tsuchiya et 223 al., 1992). The classical LSW (Bersch et al., 2007; Yashayaev et al., 2008) is built by intense 224 winter convection, when the mixing layer reaches $\sim 2000 \mathrm{~m}$ depth. Deep winter convection at these 225 latitudes is controlled by the phase of the NAO and its persistence (Dickson et al., 1996; Bersch et 226 al., 2007). Indeed, it is favoured during persistent phases of the high NAO index, such as the 227 period 1987-1994, when the winter convection reached $2400 \mathrm{~m}$ depth (Lazier et al., 2002; 228 Yashayaev, 2007), where the LSW properties reached extremal values of $2.9^{\circ} \mathrm{C}$ and 34.84 229 (Álvarez et al., 2004; Yashayaev, 2007). The thermohaline properties of the corresponding SWT 230 are consistent with the characteristic values for the classical LSW as a long-term average (Lazier, 231 1973; Dickson et al., 1996) (Fig. 3a, b; Table 2).

232 The left limit of the $\theta / S$-diagram is characterized by the Subarctic Intermediate Water 233 (SAIW), which originates in the western boundary of the NASPG (Arhan, 1990) from the mixture of 234 the warm and salty waters of the NAC with the cold and low-salinity waters of the Labrador Current 235 (Iselin, 1936; Read, 2000). The thermohaline properties of SAIW $\left(4-7^{\circ} \mathrm{C}\right.$ and $\left.\mathrm{S}<34.9\right)$ vary due to 236 its spreading and subduction in a region characterized by a complex circulation, with horizontal and 237 vertical mixing, recirculation processes and mesoscale variability, among other processes 238 (Bubnov, 1968; Arhan, 1990). Similarly to what we did in the case of SPMW and in order to better 239 depict SAIW, we defined two SWTs: SAIW 6 , which represents the fresher and relatively warm 240 variety resulting from the progressive warming of the fresher Arctic waters while mixing with central 241 waters (Fig. 3a; Table 2); and $\mathrm{SAIW}_{4}$, which represents the saltier and relatively cold variety 
242 resulting from the cooling of the saltier central waters while mixing with the Arctic waters. The

243 thermohaline properties of both SWTs follow the descriptions of Bubnov (1968) and Harvey and 244 Arhan (1988).

245 The bottom part of the $\theta /$ S-diagram shows DSOW and ISOW, which are complex mixtures 246 of several water masses. The Norwegian Sea waters overflow and entrain the overlying warm 247 saline Atlantic waters (SPMW and LSW) forming ISOW (van Aken and de Boer, 1995; Dickson et 248 al., 2002; Fogelqvist et al., 2003). To avoid the parameterization of this mixing process (as in the 249 case of MW), we defined the ISOW thermohaline properties by considering this overflow as the 250 final result of those mixing processes, and according to the definition of van Aken and Becker 251 (1996) (Fig. 3a, b; Table 2). As for DSOW, it is formed after the Nordic Seas deep waters overflow 252 and entrain Atlantic waters (SPMW and LSW) (Read, 2000; Yashayaev and Dickson, 2008). In 253 addition, some authors have reported dense Greenland shelf water cascading down to the DSOW 254 layer in the Irminger Sea (Olsson et al., 2005; Tanhua et al., 2005, 2008; Falina et al., 2012). 255 According to this and following van Aken and de Jong (2012), we modelled DSOW by two SWTs: a 256 relatively saline one (DSOW) and a relatively fresh one (the Polar Intermediate Water; PIW) (Fig. $2573 a, b ;$ Table 2). The $\theta / S$ characteristics chosen for DSOW are in agreement with the characteristics 258 of the saline variety of van Aken and de Jong (2012) and with the characteristics of DSOW after 259 crossing the sill found by Tanhua et al. (2005). PIW is an SWT with characteristics close to the low260 salinity variety of the overflow (Tanhua et al., 2005). We substituted the relatively fresh end261 member proposed by van Aken and de Jong (2012) by PIW to take into account the dense shelf 262 water intrusions, since these intrusions lie on a mixing line between PIW and the Irminger Current 263 Water (Rudels et al., 2002; Falina et al., 2012). The $\theta / \mathrm{S}$ characteristics selected for PIW are in 264 agreement with those proposed by Malmberg (1972) and Rudels et al. (2002).

265 The North East Atlantic Deep Water (NEADW) is formed as a result of different 266 entrainments that occur along the journey of ISOW through the Iceland Basin (van Aken, 2000). 267 NEADW recirculates in the Iberian Basin and mixes with the surrounding waters, including the 268 bottom waters coming from the Southern Ocean (Antarctic Bottom Water; van Aken and Becker, 269 1996). The $\theta / S$ properties of NEADW below $2500 \mathrm{~m}$ depth in this basin can be approximated as a 270 line (Saunders, 1986; Mantyla, 1994) whose end points define our SWTs representing the upper 
$271\left(\mathrm{NEADW}_{\mathrm{U}}\right)$ and lower $\left(\mathrm{NEADW}_{\mathrm{L}}\right)$ varieties of NEADW (Fig. 3a, b; Table 2). The $\theta / \mathrm{S}$ properties of

272 these two SWTs are close to those defined by Castro et al. (1998).

273 Having selected the $\theta / S$ properties for each SWT from the literature, we run the OMP

274 analysis taking the remaining chemical properties $\left(\mathrm{NO}_{3}^{0}, \mathrm{PO}_{4}^{0}\right.$ and $\left.\mathrm{SiO}_{2}^{0}\right)$ from the work of Álvarez et

275 al. (2004) and the $O_{2}^{0}$ equal to saturation as a first guess. For those SWTs not defined in Álvarez et

276 al. (2004), their first-guess chemical properties were taken as equal to those properties of the

277 nearest SWT in Álvarez et al. (2004) $\left(O_{2}^{0}\right.$ equal to saturation). The final chemical properties for

278 each SWT (those that best fit the measured data) were obtained from an iterative procedure

279 (section 2.2.2). Some of the values of $O_{2}^{0}$ were adjusted so as not to get negative values for either 280 respiration or nutrients, and to account for the disequilibrium between the $\mathrm{O}_{2}$ content in the 281 atmosphere and in the water mass at its time of formation (in the surface ocean) (Najjar and 282 Keeling, 2000; Ito et al., 2004). The uncertainties in the properties were obtained as explained in 283 section A2 of the Appendix.

\subsubsection{Methodology of the analysis}

An OMP analysis is a simple mathematical approach based on measured data that solves

the mixing between SWTs by a least square method constrained to be positive definite (section A1 of the Appendix). The methodology applied in this work consists of two steps (Pardo et al., 2012).

288 First, the 14 SWTs were grouped into a total of 11 mixing figures (Fig. 3c), which are subsets of 289 SWTs that are susceptible to mixing. The term figure refers to the geometrical space in the $\theta / S$ 290 plane formed by 2 SWTs (line segment), 3 SWTs (triangle), 4 SWTs (square), etc. Actually, the 291 mixing figures are $n$-dimensional spaces. These mixing figures were selected based on the 292 characteristics and/or dynamics of the SWTs in the region of study. In the first step of the 293 methodology we solved a classical OMP (cOMP) analysis (Tomczak, 1981), which is based only 294 on conservative variables $\left(\theta, \mathrm{S}, \mathrm{SiO}_{2}\right.$, "NO" and "PO"; see section $\mathrm{A} 1$ of the Appendix), for each 295 water sample in each one of the mixing figures. In this way we assigned to each water sample the mixing figure whose mixing best explains its properties. In the second step we solved an extended 297 OMP (eOMP) analysis to obtain the $X_{i} \mathrm{~s}$ in each water sample for the mixing figure selected in the 
298 previous step. The eOMP analysis includes conservative $(\theta$ and $\mathrm{S})$ and non-conservative $\left(\mathrm{NO}_{3}\right.$, $299 \mathrm{PO}_{4}, \mathrm{SiO}_{2}$ and $\mathrm{O}_{2}$ ) variables. By taking into account the biogeochemical process of remineralisation 300 of the organic matter, we can include non-conservative variables (for more details about the 301 methodology see section A1 of the Appendix). We restricted the whole OMP analysis (cOMP and $302 \mathrm{eOMP}$ ) to the water samples with pressure $\geq 50 \mathrm{dbar}$, to avoid the non-conservative behaviour of $\theta$ 303 and $S$ in the surface layer due to air-sea interactions after the last maximum of winter convection. 304 Additionally, we included special SWTs for the regions of intense air-sea interactions (section 305 2.2.1). We also avoided the input of high percentages of fresh water over the Greenland shelf by 306 restricting the analysis in this region to water samples with $S>34.7$ (Daniault et al., 2011). Some of the SWTs were geographically constrained (Álvarez et al., 2004) according to the spreading of the water masses: MW was restricted south of the NAC front; DSOW and IrSPMW were restricted to the Irminger Basin; PIW was restricted to stations over the Greenland slope (in mixing figure 1; Fig. 3c) since it is part of the East Greenland Current (Pickart et al., 2005), and within the DSOW mixing figure (in mixing figure 3) since it is assumed to contribute to DSOW (Falina et al., 2012); and LSW was not allowed in the East Greenland Current (Falina et al., 2012; von Appen et al., 2014).

To reduce the error of the whole OMP analysis, an iterative process was performed for nutrients (Álvarez et al., 2004), since they accumulate the highest errors (section A1 of the Appendix). At each iteration we obtained new values of the nutrients for each SWT from $X_{i} s$ and

317 the measured data (eOMP equations). These new estimated values were assigned to the SWTs 318 and the methodology was re-run. The process finishes when an asymptote is found in the value of 319 the total residual of the analysis (eOMP) (in this work five iterations were performed). The iterative 320 process improves the definition of the SWTs, thereby also improving the accuracy of the 321 methodology.

322 We tested the robustness of the methodology through a perturbation analysis (Lawson and 323 Hanson, 1974), where the physicochemical properties of each SWT (Álvarez et al., 2004; Pardo et 324 al., 2012) and of each water sample (Álvarez et al., 2014) were modified by introducing normally 325 distributed random numbers (section A2 of the Appendix). The resulting uncertainties in the $X_{i} \mathrm{~s}$ range were between 0.015 and 0.13 (Table 2), indicating that the methodology is robust. 
327 Additionally, our model is consistent since its residuals lack a tendency with depth (section A3 of

328 the Appendix) and the Standard Deviations of the Residuals remain low, slightly higher than the 329 corresponding measurement error (Table 2). Besides, the model's ability to reproduce the 330 measured values is given as the correlation coefficient $\left(r^{2}\right)$ between the measured (water samples)

331 and the expected values for the SWTs properties (values of the properties of each water sample 332 obtained by substituting $X_{i} s$ in the system of equations; section $A 1$ of the Appendix). The $r^{2}$ values 333 are higher than 0.94 , indicating again the reliability of our methodology.

334 When evaluating the water mass distributions derived from an OMP analysis, it should be 335 taken into account that the properties that define the SWTs are time invariant; hence, changes in 336 the properties of the water masses over time are reflected through water mass redistributions. 337 Therefore, it is possible that some of the changes in the distribution of the SWTs may actually 338 reflect inter-annual variations in the water mass properties not taken into account in the OMP set339 up, and not only an increase/reduction of its extension. This affects water masses such as LSW 340 and SPMW, whose properties vary from year to year due to formation processes and air-sea 341 interaction differences.

\subsection{Velocity field}

The velocity fields in the sections are required to compute the volume transports by water mass. The velocity fields were obtained from the results of previous studies realized over the same sections using linear box inverse models. The inverse model configurations for $4 x$ and OVIDE 2002 have been described by Lherminier et al. (2007), for OVIDE 2004 by Lherminier et al. (2010),

347 for OVIDE 2006 by Gourcuff et al. (2011), and for OVIDE 2008 and 2010 by Mercier et al. (2015).

The inverse model is based on the least-squares formalism, which provides errors on the

349 velocities and associated quantities such as the magnitude of AMOC (estimated in density 350 coordinate) and the heat flux (Lherminier et al., 2010). The inverse model was constrained by 351 direct Acoustic Doppler Current Profiler velocity measurements and by an overall mass balance of $3521 \pm 3$ Sv to the North (Lherminier et al., 2007, 2010). 
The inverse model computes the absolute geostrophic transports orthogonal to the section.

354 The Ekman transport is deduced from the wind fields averaged over the cruise period and added 355 homogeneously in the first 40 metres (Mercier et al., 2015). The transport estimates of the inverse 356 model across OVIDE have been validated by favourable comparisons with independent 357 measurements (Gourcuff et al., 2011; Daniault et al., 2011; Mercier et al., 2015).

\subsection{Combining the water mass distributions with the velocity fields}

The combination of the $X_{i} \mathrm{~s}$ ( $\mathrm{i}=1$ to 14 ) obtained using the OMP analysis with the velocity fields allowed us to obtain the volume transport of each SWT in the whole water column (Álvarez et al., 2004).

The $X_{i}$ s were obtained at each measured point (i.e., bottle depth) for each hydrographic station, whereas the geostrophic and Ekman components of the flow were estimated at middistance between two hydrographic stations (defining a station pair) with a vertical resolution of 1 dbar. To match the velocity field, the SWT distributions were linearly interpolated at each dbar, and averaged in station pairs. The velocity field was obtained from the CTD downcast and the biogeochemical measurements (leading to the $X_{i} \mathrm{~s}$ ) were performed during the CTD upcast. To better match up both fields and compensate for vertical displacements of the water masses between the CTD downcast and upcast, we used density coordinates instead of pressure coordinates to interpolate the $X_{i} \mathrm{~s}$. To obtain $X_{i} \mathrm{~s}$ until the bottom depth of each station pair, the shallower station profile in each station pair was extended until the maximum depth of the station pair by copying down the $X_{i}$ values of the deepest measured point available.

Data of the upper layer (pressure $\leq 50 \mathrm{dbar}$ ) and of the Greenland shelf waters with $\mathrm{S}<$ 34.7, excluded from the OMP analysis, were appropriately reconstructed. The shallowest mixing contributions at each station of the upper layer were extrapolated up to the surface by keeping the same $X_{i}$ values. In areas close to the Greenland shelf, water samples with $S<34.7$ were substituted by the nearest water sample included in the analysis. 
The water mass distributions were obtained for each repeat of the OVIDE section by means

of an OMP analysis (section 2.2). It is important to remember that the water mass distributions presented in this study should be regarded as a best estimate and serve to illustrate the relative importance of the water masses, since the definitions of the SWTs in the OMP analysis mostly condition the distribution and the maximum contribution achieved by each SWT. Additionally, we have to point out that NEADW $U$ is not shown because it was considered as a composite SWT (Álvarez et al., 2004; Carracedo et al., 2012) that can be derived from the mixing of $1.5 \%$ of MW, $18.4 \%$ of LSW, $29.5 \%$ of ISOW and $50.5 \%$ of NEADW (decomposition based on $\theta$, S and $\mathrm{SiO}_{2}$ content in the different water masses and on the work of van Aken (2000)). In this section, we describe and discuss the relevant features of the distributions of each SWT for the mean result of the OVIDE period (2002-2010) (Fig. 4).

\subsection{Upper waters}

The Central Waters $\left(\mathrm{ENACW}_{16}+\mathrm{ENACW}_{12}\right)$ occupy the upper eastern part of the OVIDE section from the Iberian Peninsula until the Reykjanes Ridge (Fig. 4a), representing an average of $14.58 \pm 0.14 \%$ of the total volume of the five sections. They follow the $\theta$ maximum and the $\mathrm{SiO}_{2}$ minimum over the Iberian Basin (Fig. 2a, e). Their distribution is associated with the circulation of the NAC, being the $\theta / S$ front caused by the northern branch of the NAC (located at $25^{\circ} \mathrm{W}$ in the OVIDE sections, Fig. 2a, b) the western limit of the Central Waters distribution. The Central Waters main core extends westwards, reflecting the cyclonic circulation of the Central Waters in the Iceland Basin and their southward flow over the eastern flank of the Reykjanes Ridge (Read, 2000; Pollard et al., 2004).

The main core of IcSPMW $\left(\mathrm{SPMW}_{8}+\mathrm{SPMW}_{7}\right)$ is over the Reykjanes Ridge (Fig. 4c). 401 IcSPMW reaches the surface in the Irminger Basin, although it is formed in the Iceland Basin by 402 the transformation (air-sea interactions) of the Central Waters (Thierry et al., 2008). This indicates 403 that, at the time of OVIDE sections (summer), the surface waters in the Iceland Basin were warmer 404 than $8^{\circ} \mathrm{C}$. Furthermore, SAIW is also present in the surface waters of this basin, where it mixes 
406 SPMW from the Iceland Basin to the Irminger Basin by the NAC (Irminger Current) (Brambilla and 407 Talley, 2008).

$408 \quad$ IrSPMW extends from the Greenland slope until the Reykjanes Ridge (Fig. 4d), with its 409 main core over the Greenland slope. This distribution could indicate that the major region of 410 formation of IrSPMW could be the NW of the Irminger Basin (Brambilla and Talley, 2008), from 411 where the East Greenland Irminger Current would transport it until the OVIDE section. This SWT 412 can be treated as a precursor of the upper LSW (Pickart et al., 2003). The continuity of the 413 distributions of the Central Waters, IcSPMW and IrSPMW indicates that IrSPMW is the final 414 product of the transformation of the Central Waters due to air-sea interaction processes 415 (McCartney and Talley, 1982; Brambilla and Talley, 2008), IcSPMW being the intermediate point of 416 the transformation.

\subsection{Intermediate waters}

SAIW $\left(\right.$ SAIW $_{6}+$ SAIW $\left._{4}\right)$ is present in the upper layers of the northern half of the OVIDE sections (Fig. 4b). The distribution of SAIW shows a maximum in the Iceland Basin associated with

420 its advection from the Labrador Sea within the NAC and its subduction beneath the Central Waters 421 (Bubnov, 1968; Arhan, 1990; Read, 2000). SAIW suffers a sharp decline once it encounters the 422 NAC, but its contribution is significant until $600 \mathrm{~m}$ depth, where it still represents percentages 423 greater than $25 \%$. East of the Rockall Bank (Fig. 1), SAIW deepens until intermediate water 424 depths, where it overlies MW (Pollard et al., 1996). In fact, SAIW and MW contribute together to 425 their surrounding waters in the region southeast of the NAC (Figs. 1 and 4b, d) (Harvey and Arhan, 426 1988).

427 The main core of MW is located around $1200 \mathrm{~m}$ depth off the shelf of the lberian Basin (Fig. $4284 \mathrm{~d}$, see the tongue of maximum $\mathrm{S}$ and minimum $\mathrm{O}_{2}$ in Fig. $2 \mathrm{~b}, \mathrm{c}$ ), with a maximum of $83.4 \pm 0.9 \%$ 429 coinciding with the $S$ maximum of $36.28 \pm 0.01(n=5$; where $n$ is the number of cruises). This main 430 core is associated with the northward flow of MW (Reid, 1979) and extends westwards, which 431 could be associated with its transport by meddies (Mazé et al., 1997) and by the Azores 432 countercurrent (Carracedo et al., 2014). 
LSW is the dominant SWT in the sections $(35.0 \pm 0.6 \%$ of the section volume, $n=5$; Fig.

$4344 \mathrm{e})$. It mainly extends from 1000 to $2500 \mathrm{~m}$ depth, coinciding with the $\mathrm{S}$ minimum $(34.91 \pm 0.02)$ 435 and a relative $\mathrm{O}_{2}$ maximum $\left(285 \pm 2 \mu \mathrm{mol} \mathrm{kg}{ }^{-1}\right)$ found in all the three basins (Fig. $\left.2 \mathrm{~b}, \mathrm{c}\right)$. LSW 436 presents two main cores separated by the Reykjanes Ridge, which correspond to the different 437 pathways of its circulation (Pickart et al., 2003; Álvarez et al., 2004). This "gap" separating the two 438 LSW cores suggests a relatively strong mixing around and over the Reykjanes Ridge (Ferron et al., 439 2014), where the presence of fractions greater than $20 \%$ of ISOW and IcSPMW induces a 440 decrease in LSW. This erosion of the LSW core is also reflected by a reduction of the S minimum 441 over the Reykjanes Ridge (Fig. 2b). Moreover, this is the location of the water mass described as 442 the Icelandic Slope Water by Yashayaev et al. (2007), which is defined as a result of the direct 443 mixing of ISOW with Atlantic waters, mixing represented in our work by the mixing figure 4 (Fig. 444 3c). In agreement with the work of Read (2000), the depth of the LSW core in the Irminger Basin is 445 shallower than the one spreading across the Iceland and Iberian Basins, although they stay at the 446 same density (see isopycnal $\sigma_{1}=32.42$, dashed line on Fig. 4e; where $\sigma_{1}$ is potential density 447 referenced to $1000 \mathrm{dbar}$ ). The contribution of LSW in the south-eastern part of the sections is high 448 (reaching maximum values of $76 \pm 1 \%, n=5$ ), emphasizing the influence of LSW until areas close 449 to the Iberian Peninsula (Tsuchiya et al., 1992; Arhan et al., 1994; Paillet et al., 1998). Moreover, 450 the volume occupied by LSW gradually decreases from the Irminger Basin to the Iberian Basin. It 451 represents $45 \pm 1 \%(n=5)$ of the volume of the Irminger Basin (defined between the Greenland 452 slope and the Reykjanes Ridge), $45 \pm 1 \%$ of the volume of the Iceland Basin (defined from the 453 Reykjanes Ridge until $25.5^{\circ} \mathrm{W}$ ) and $30.3 \pm 0.5 \%$ of the volume of the Iberian Basin (note that the 454 volumes of the basins refer to the volumes at the section location, and the volumes per water mass 455 are computed by weighting the volume of the basin by the SWT contribution).

\subsection{Overflows and deep waters}

ISOW comes from the Iceland-Scotland sills and flows southwards along the eastern flank 458 of the Reykjanes Ridge, where its main core is found (Fig. 4b). This main core is located at depths 459 greater than $2300 \mathrm{~m}$, with maximum percentages of $90 \pm 2 \%(n=5)$, where the $\theta / \mathrm{S}$ properties are 
$4602.59 \pm 0.03^{\circ} \mathrm{C}$ and $34.979 \pm 0.002$, respectively. From this region the core extends eastwards 461 between 2000 and 4000 m depth, reaching values of $10 \%$ in the Iberian Abyssal Plain (Fig. 1). 462 This eastward extension could reveal that some ISOW must bypass the CGFZ and flow into the 463 West European Basin. This feature is captured by the OMP analysis, since it is capable of 464 capturing the significant fractions of the water masses better than the classical water mass 465 descriptions. ISOW is also detected at the bottom in the central and eastern regions of the Irminger 466 Basin, associated with its northward spreading after crossing the CGFZ (Dickson and Brown, 1994; 467 Saunders, 2001). These findings could also be related to the northward flow of ISOW mainly in the 468 interior part of the Irminger Basin (Sarafanov et al., 2012).

The deepest part of the Greenland continental slope is occupied by DSOW (Fig. 4a). The 470 distribution of this water mass can be traced in the vertical sections of the OVIDE mean properties 471 (Fig. 2) as a minimum of $\theta\left(<2^{\circ} \mathrm{C}\right)$, a maximum of $\mathrm{O}_{2}\left(>280 \mu \mathrm{mol} \mathrm{kg}{ }^{-1}\right)$ and a relative minimum of 472 nutrients. The inclusion of PIW in the analysis is an attempt to model the entrainment of shelf 473 waters into the deep waters of the Irminger Basin (Tanhua et al., 2008; Falina et al., 2012; von 474 Appen et al., 2014). The presence of PIW (Fig. 4f), even though in a very narrow area, supports 475 the statement of the existence of certain dynamical processes that link the East Greenland shelf 476 waters with the deep overflows.

$477 \quad \mathrm{NEADW}_{\mathrm{L}}$ is the dominant water mass in the lberian Basin from $2000 \mathrm{~m}$ depth to the bottom, 478 with the main core below $\sim 3500 \mathrm{~m}$ depth (Fig. 4f). The distribution of this water mass follows the 479 high $\mathrm{SiO}_{2}$ concentrations at the bottom of the Iberian Basin $\left(>20 \mu \mathrm{mol} \mathrm{kg}^{-1}\right.$; Fig. $\left.2 \mathrm{e}\right)$, which are 480 coupled with high concentrations of $\mathrm{NO}_{3}$ and $\mathrm{PO}_{4}$ (Fig. 2d, f, respectively). The high $\mathrm{SiO}_{2}$ levels 481 reflect the influence of Antarctic Bottom Water (van Aken and Becker, 1996). The NEADW 482 isolines shallow eastwards due to the general deep eastern boundary upwelling of this water mass 483 along the coast of the Iberian Peninsula (Arhan et al., 1994). The northern part of the distribution of 484 NEADW $W_{L}$ is affected by the influences of LSW and ISOW.

\section{4. Time variability of the water mass distributions between 1997 and 2010}


In this section, we select SPMW (ICSPMW + IrSPMW), LSW and the deep overflows

487 (DSOW and ISOW) to describe and discuss their variability from 1997 to 2010 (Fig. 5). It should be 488 mentioned that the different section pathways (Fig. 1) could generate differences in the SWT 489 distribution patterns between the $4 x$ and OVIDE sections. The overlapping of the METEOR and 490 OVIDE sections allows us to distinguish between the differences in the SWTs distributions due to 491 the different section pathways, and the inter-annual variability.

From the comparison of the LSW distributions in both cruises of 1997, we can conclude that 493 for the Irminger Basin the difference in the section pathway between the $4 x$ and OVIDE sections is 494 negligible, whereas for the Iceland Basin and around the Reykjanes Ridge it is an important 495 component of the variability of the LSW distributions (Fig. 5). In the Irminger Basin, from 1997 to 4962010 the contribution of LSW gradually decreases, which is in agreement with the almost complete 497 disappearance of the LSW signal found in 2007 by de Jong et al. (2012). LSW represents $58 \%$ of 498 the volume of the Irminger Basin in 1997, then its importance decreases over time, representing 50 $499 \%$ for 2002 , with a sharp decrease in 2006 when it drops to $43 \%$, a percentage that remains until 500 2010. The LSW maximum in the Iceland Basin decreases more slowly than the one in the Irminger 501 Basin, meaning that in 2004 the fractions of the core in the Iceland Basin are higher (> $95 \%$ ) than 502 those of the core in the Irminger Basin (<90\%). This contrast is most noticeable in 2006 due to 503 the sharp decrease in the fractions of LSW in the Irminger Basin. In the West European Basin (Fig. 504 1) the greatest change in the fractions of LSW takes place in 2008 , when the extension of the core 505 is reduced in both the Iceland and the West European Basins, a reduction that continues in 2010. 506 However, the volume occupied by LSW in the Iberian Basin is almost constant over time (30.3 \pm $5070.5 \%$ for the period 2002-2010), which indicates that the large inter-annual variability of the 508 properties in its formation region attenuates due to mixing over the length and timescales of the 509 transit from the Labrador Sea (Cunningham and Haine, 1995; Paillet et al., 1998). The difference in 510 years between the deepening and total extension of LSW could be related to the changes in the 511 volume of LSW formed. Between 1987 and 1995 the change in the NAO index led to the 512 diminution in volume and also the warming and salinization of LSW over time (Lazier et al., 2002; 513 Yashayaev, 2007). These changes in the LSW properties are solved by the OMP analysis by 514 adding more SPMW. 

two sections carried out in 1997 (Fig. 5), which indicates that the section pathway influences the

517 SPMW distribution since both cruises took place in the same time frame. The main path of the 518 NAC around the Reykjanes Ridge is located north of the $4 x$ section location (Fig. 1) so that the

519 fractions of SPMW observed at the 4x location are lower than at the OVIDE location. Meanwhile, 520 the METEOR section presents an SPMW distribution similar to those of the OVIDE sections. 521 Between 1997 (METEOR) and 2010, the importance of SPMW increases, rising from $24 \%$ to $30 \%$ 522 of the volume of the Irminger Basin, with a rate of increase of $0.5 \%$ per year $\left(r^{2}=0.93\right)$, driven 523 mainly by the increase in the upper $1000 \mathrm{~m}$ over the Reykjanes Ridge $\left(0.7 \%\right.$ per year, $\left.r^{2}=0.95\right)$. 524 This change may be related to the difference in the properties of the water masses at their 525 formation regions. Since the end of the 1990s, the upper-ocean and upper intermediate waters of 526 the NASPG have been getting saltier and warmer due to the redistribution of subpolar and 527 subtropical waters caused by the NAO-induced slowdown and contraction of the NASPG (Bersch, 528 2002; Hátún et al., 2005; Sarafanov, 2009; de Boisséson et al., 2012). Thus, the 1997 section 529 presents fresher waters than the 2000s sections, and the OMP emplaces there less SPMW and 530 more LSW. Moreover, the increasing amount of SPMW in the centre of the Irminger Basin could be 531 associated with the reduction of the deep convection in the Labrador Sea, which resulted in a 532 shallower variety of LSW (Pickart et al., 1996; Stramma et al., 2004; Bersch et al., 2007). The 533 thickening observed in the SPMW distributions could indicate a salinization of LSW, solved by the 534 OMP by adding greater fractions of SPMW.

535 The inter-annual variability of the depth, location and importance of LSW and SPMW seems 536 to be connected. These results are in agreement with the interplay that exists between these water 537 masses (Bersch et al., 1999). The upper parts of the Irminger Basin gain SPMW and lose LSW 538 over time, demonstrating the ability of our OMP methodology to capture the different vintages of 539 LSW formed over time (Yashayaev et al., 2008).

540 The distribution of ISOW is also influenced by the section pathway that is reflected by the 541 differences in its distribution between the two 1997 cruises. For the 4x section the percentages of 542 the ISOW core located over the eastern flank of the Reykjanes Ridge fall below $70 \%$, whereas for 543 the METEOR section it reaches percentages greater than $80 \%$ (Fig. 5). This difference could be 
544 explained by the flow of part of ISOW through gaps in the Reykjanes Ridge located north of the

545 CGFZ, between the METEOR and 4x sections, as found by Xu et al. (2010). The existence of 546 various deep passages between the locations of the sections (Fig. 1) may reduce the arrival of

547 ISOW to the $4 x$ section. The distribution of ISOW in the Irminger Basin also differs between the $4 x$ 548 and METEOR sections. The $4 \mathrm{x}$ section is located just after the CGFZ, so that the ISOW 549 distributions on both sides of the ridge are similar. Meanwhile, in the METEOR section, the great 550 distance between the fracture zone and the section causes ISOW to arrive more diluted at the 551 section location after flowing anticyclonically around the ridge. For the same section pathway 552 (METEOR-OVIDE), we found slight inter-annual changes in the distributions of ISOW on both 553 sides of the Reykjanes Ridge. The core over the eastern flank of the ridge expands and contracts 554 between cruises, which could reflect the inter-annual variability of the properties and sources of 555 ISOW (Sarafanov et al., 2010). For the Irminger Basin, the ISOW influence increases over time, 556 with the greatest change between 1997 (2\% of volume) and 2002 (10\%), increasing in importance 557 until 2010 (15\%), although with some inter-annual variability. The great difference between the 558 ISOW distributions of the Irminger Basin in 1997 (METEOR) and 2002 could be related to the 559 different LSW distribution on the two cruises. In 1997, after a period of high NAO index when large 560 amounts of LSW were formed (Lazier et al., 2002; Yashayaev, 2007), LSW occupied almost the 561 whole Irminger Basin, leaving little space for ISOW. In 2002, the reduction of the percentages of 562 LSW allowed more ISOW to enter the Irminger Basin. These results are also supported by the 563 increase of $S$ in the Irminger Basin in the density range of ISOW found by Sarafanov et al. (2010). 564 Since the properties that define an SWT are time invariant, the OMP analysis solves this increase 565 of S by giving more presence to ISOW and less to LSW. This is also consistent with the increase of 566 S in LSW (Lazier et al., 2002; Pickart et al., 2003; Kieke et al., 2007).

567 For 1997, DSOW seems to be colder at the 4x location than at the OVIDE location, which is 568 reflected by lower percentages of DSOW and higher of PIW (Fig. 5). This could indicate that (i) at $5694 x$ location the spill jet, represented by PIW, is not completely mixed with DSOW and the two 570 SWTs can be more easily distinguished; and (ii) the existence of strong mixing between the two 571 section locations led to a well-defined DSOW at the OVIDE location. Between METEOR and 2010, 572 the DSOW distributions present no apparent trend at inter-annual timescales. In 2002 and 2004 
573 the PIW influence in the DSOW layer is greater than in the other years, which is in agreement with

574 the entrainment events observed by Falina et al. (2012). Adding the PIW contributions of mixing 575 figure 3 (Fig. 3c) to those of DSOW, we can observe this increase in the overflow volume. In both 576 years, the DSOW contributions are greater, reaching more than $5.0 \%$ of the volume of the 577 Irminger Basin, while in the other cruises its percentages do not exceed $4.5 \%$. Probably, these 578 changes could be associated with inter-annual variability in the water sources and transports of the 579 overflows (Falina et al., 2012), which could ultimately be related to changes in the atmospheric 580 forcing (Macrander et al., 2005), but we lack sufficient data to relate these changes to a given 581 timescale.

582 5. Water mass volume transports, recirculation and transformations in the Subpolar North 583 Atlantic

584 For each OVIDE cruise the $X_{i}$ s were combined with the absolute geostrophic velocity field 585 (section 2.4) to obtain the water mass volume transports. Then we computed the mean water mass 586 volume transports for the period 2002-2010 and integrated them along the section to obtain the 587 net water mass volume transports (represented in Sverdrup; $1 \mathrm{~Sv}=10^{6} \mathrm{~m}^{3} \mathrm{~s}^{-1}$ ) (Fig. 6). The water 588 mass volume transports were calculated perpendicular to the sections and are positive northwards. 589 Errors were computed by weighting the velocity errors by the $X_{i}$ s. The velocity errors were 590 computed at the reference level using the error covariance matrix of the inversion (Mercier, 1986; 591 Lherminier et al., 2007, 2010). It is important to note that the water mass volume transport 592 estimates are sensitive to the distribution of the SWTs.

593 The water masses that contribute to the northward transport in the section are the Central 594 Waters (11.6 $\pm 1.2 \mathrm{~Sv})$, IcSPMW (2.6 $\pm 1.5 \mathrm{~Sv})$, SAIW (2.2 $\pm 0.4 \mathrm{~Sv})$ and MW (0.2 $\pm 0.4 \mathrm{~Sv})$ (Fig. 595 6). These are the first estimates of the transports of the Central Waters, SPMW and SAIW in the 596 Subpolar North Atlantic apart from the transports of the Central Waters and SAIW reported for the $5974 x$ section by Álvarez et al. (2004) (10.3 and 2.9 Sv, respectively). Our MW transport is lower than 598 that reported by Álvarez et al. (2004) and Schmitz (1996). This may be due to the variability 599 derived from its transport by meddies (Arhan and King, 1995; Mazé et al., 1997). 
The transformation of the above-cited water masses leads to the formation of IrSPMW,

601 which transport (-8.8 $\pm 0.9 \mathrm{~Sv}$; Fig. 6$)$ is concentrated in the East Greenland Irminger Current. This water mass represents an important fraction of the $-22.1 \pm 3.2 \mathrm{~Sv}$ of the East Greenland Irminger 603 Current estimated for the OVIDE sections of 2002 and 2004 by Lherminier et al. (2010). IrSPMW is 604 the precursor of LSW, whose net transport across the OVIDE section is southwards $(-0.9 \pm 1.8 \mathrm{~Sv})$. 605 This net southward transport of LSW, in agreement with a moderate formation of LSW in the 606 Irminger Basin (Pickart et al., 2003), is explained by the strong southward transports found in the 607 East Greenland Irminger Current, where small amounts of LSW lead to great southward transports. 608 Lherminier et al. (2007) reported a net northward export of LSW in the OVIDE section, while Bacon 609 (1997) found a net transport of $-1 \mathrm{~Sv}$ of LSW in a section close to the OVIDE section. The most 610 likely explanation for the difference between our results and the two previous ones could lie in the 611 specificities of the distributions obtained from the OMP analysis. The SWTs distributions are not 612 defined by isopycnal ranges but as dilution from a "pure" SWT, so the OMP methodology assesses 613 all the water mass contributions, even those outside the core of the water mass. This feature 614 together with the inter-relation between LSW, SPMW and ISOW in the Irminger Basin (sections 3 and 4) could result in this kind of difference in the transport estimates.

The water masses coming from the sills are PIW, DSOW and ISOW. The PIW transports 617 were split into two main cores: a shallow one associated with mixing figure 1, and a deep one 618 associated with mixing figure 3 (Fig. 3c; section 2.2.2). For the shallow core of PIW the net 619 transport is $-1.3 \pm 0.1 \mathrm{~Sv}$ (Fig. 6). This transport is slightly lower than those reported by Pickart et 620 al. (2005) (barely $-2 \mathrm{~Sv}$ ) and Falina et al. (2012) (-2.4 $\pm 0.3 \mathrm{~Sv}$ as mean transport for 2002-2004). 621 This could be because the transports associated with the deep core of PIW were added to those of 622 DSOW. Nevertheless, it is in agreement with the $-1.3 \mathrm{~Sv}$ of upper waters estimated to enter the 623 Irminger Basin from the Nordic Seas (Hansen and Österhus, 2000). The transport of DSOW across 624 the OVIDE section is $-2.5 \pm 0.3 \mathrm{~Sv}$, which is in good agreement with the estimates of Ross (1984) 625 (from -2 to -3 Sv), Eden and Willebrand (2001) (-2.5 Sv), and Lherminier et al. (2010) (-2 Sv, for 626 the OVIDE sections of 2002 and 2004). However, our estimate is slightly lower than the -3 Sv 627 found by Dickson and Brown (1994), the $-3.5 \pm 1.6 \mathrm{~Sv}$ found by Macrander et al. (2005) and the $6283.4 \pm 1.4 \mathrm{~Sv}$ found by Jochumsen et al. (2012). Since in this study the assessment of the water 
629 mass volume transports is based on dilutions of a "pure" SWT, it would be expected to have lower 630 volume transports than those estimated by isopycnals. These underestimates are compensated by 631 the mixing with other SWTs (ISOW and LSW). The net transport of ISOW is $-2.7 \pm 0.8 \mathrm{~Sv}$, a result supported by the $-3.2 \pm 0.5 \mathrm{~Sv}$ reported by Saunders (1996), the $-3.6 \pm 0.5 \mathrm{~Sv}$ reported by van 633 Aken and Becker (1996), the $-2.5 \pm 0.9 \mathrm{~Sv}$ reported by Lherminier et al. (2007) and the $-3.7 \pm 0.8$ 634 Sv reported by Sarafanov et al. (2012). Finally, NEADW $\mathrm{L}_{\mathrm{L}}$ also contributes to the net pull of the 635 deep waters in the NASPG. The net transport of this water mass ( $0.6 \pm 1.2 \mathrm{~Sv})$ is comparable with 636 the $1.1 \mathrm{~Sv}$ reported by van Aken and Becker (1996). In a recent study, Mercier et al. (2015) estimated the magnitude of the upper and lower limbs of the AMOC (in density coordinates) for the OVIDE sections. These authors reported a magnitude of the upper limb of the AMOC of $16.2 \pm 2.4 \mathrm{~Sv}$; and of $-15.5 \pm 2.4 \mathrm{~Sv}$ for the AMOC 640 lower limb for the OVIDE period (2002-2010). Considering the isopycnal that separates the upper 641 and lower limbs in Mercier et al. (2015) $\left(\sigma_{1}=32.15\right)$, the upper limb of the AMOC in our study is 642 represented by the Central Waters, IcSPMW and SAIW. We also included the net northward 643 transport of MW (Fig. 6) in the AMOC upper limb. These flows altogether result in an AMOC upper $644 \operatorname{limb}$ of $16.6 \pm 1.5 \mathrm{~Sv}$ for the OVIDE period. These upper AMOC contributors resemble the subtropical (Central Waters) and subpolar (SAIW and ICSPMW) components of the AMOC at the 646 OVIDE sections described by Desbruyères et al. (2013). The lower limb of the AMOC is constituted 647 by IrSPMW, PIW, LSW, ISOW, DSOW and NEADWL, resulting in a southward transport of $-15.6 \pm$ $6482.5 \mathrm{~Sv}$. Although in our study the water masses that contribute to the upper and lower limbs of the AMOC may overlap both limbs, our approach is in good agreement with the findings of Mercier et al. (2015). Combining the $X_{i}$ s of the $4 x$ section, obtained using the OMP methodology, with the velocity field of the section (Lherminier et al., 2007), we revaluated the water mass volume transports of the $4 x$ section reported by Álvarez et al. (2004). For this section, the magnitudes of 653 the upper and lower limbs of the AMOC obtained from the water masses contributing to each limb 654 are $23.3 \pm 1.2 \mathrm{~Sv}$ and $-21.1 \pm 1.8 \mathrm{~Sv}$, respectively. The difference with respect to the magnitude of 655 the AMOC for the OVIDE period is explained by the greater transports in 1997 of the Central 656 Waters (17.4 $\pm 1.2 \mathrm{~Sv})$, IrSPMW (-12.0 $\pm 0.3 \mathrm{~Sv})$ and PIW $(-3.1 \pm 0.1 \mathrm{~Sv})$. Our results support the findings of Mercier et al. (2015), who concluded that the decrease in the northward subsurface 
658 transport of the AMOC from 1993 to 2010 was balanced, at least partially, by a decrease in the 659 southward export of the intermediate waters in the western Irminger Basin. These changes could 660 be linked to a change in the circulation in response to a transition from previously high to low NAO 661 indices over this time span (1997-2000s).

662 Taking advantage of the estimated water mass volume transports, we also inferred the 663 water mass circulation and transformation in the Subpolar North Atlantic based on four boxes 664 defined following Lherminier et al. (2010) and limited to the south by the OVIDE section and to the 665 north by the Greenland-Iceland-Scotland sills (Fig. 7). The region east of the Reykjanes Ridge will 666 be referred to as the East North Atlantic (ENA) Basin and the region west of the Reykjanes Ridge 667 as the Irminger Basin. The final four boxes were obtained by dividing both basins vertically by the 668 isopycnal $\sigma_{2}=36.94$, which traditionally defines the upper bound of the deep waters. Considering 669 that no passages deeper than this isopycnal exist in the ridge between Iceland and the OVIDE 670 section, this isopycnal also separates the water masses that can cross the Reykjanes Ridge (upper 671 boxes) from those that cannot (lower boxes), which sets an additional constraint on the volume 672 budgets. The water mass volume transports are considered positive when entering the boxes. In order to obtain the volume budgets of the boxes, we considered the volume transports 674 estimates through the Greenland-Iceland-Scotland sills available in the literature (Fig. 7, grey 675 numbers). In the ENA Basin, $-7 \mathrm{~Sv}$ of relatively warm water $\left(>7^{\circ} \mathrm{C}\right)$ flow north-eastwards past the 676 Faroes (Fig. 1) (Schmitz and McCartney, 1993; van Aken and Becker, 1996; Hansen and 677 Österhus, 2000), while 3 Sv enter the basin via the overflow waters (Olsen et al., 2008). In the 678 Irminger Basin, 1.3 Sv of upper waters (Hansen and Österhus, 2000) and 3 Sv of overflow waters 679 (Olsen et al., 2008) enter this basin from the Nordic Seas, whereas -1 Sv of Atlantic water exits this 680 basin towards the Nordic Seas (Hansen and Österhus, 2000). The volume transports at the 681 southern limit of the boxes (OVIDE section) are the mean volume transports across the OVIDE 682 sections (section 3).

683 The net volume transport in the ENA Basin across the OVIDE section is $13.4 \pm 4.7 \mathrm{~Sv}$ and 684 across the Iceland-Scotland sills is $-4 \mathrm{~Sv}$ (Fig. 7a, c). As a result, $9.4 \pm 4.7 \mathrm{~Sv}$ should flow from the 685 ENA Basin to the Irminger Basin over the Reykjanes Ridge. This is corroborated by the volume budget of the Irminger Basin, where the difference between the net volume transport across the 
OVIDE section $(-12.6 \pm 4.7 \mathrm{~Sv})$ and that across the Greenland-Scotland sills $(3.3 \mathrm{~Sv})$ is $-9.5 \pm 4.7$

688 Sv. These estimates are very similar to the $11.7 \pm 2.1$ Sv estimated by Lherminier et al. (2010) for the mean of the 2002-2004 OVIDE sections and to the $9.1 \pm 1.8$ Sv estimated by Sarafanov et al. (2012) for the region between $59.5^{\circ} \mathrm{N}$ and the Greenland-Iceland-Scotland sills.

Of the $3 \mathrm{~Sv}$ of overflow waters entering the lower ENA box, only $-1.3 \pm 2.6$ Sv exit this box

692 across the OVIDE section (Fig. 7c). This implies that $1.7 \pm 2.6$ Sv should upwell and become part 693 of the upper ENA box. In fact, these $1.7 \pm 3.9 \mathrm{~Sv}$ are necessary in the upper ENA box to balance 694 the volume transports (Fig. 7a). For the upper Irminger box, $0.3 \mathrm{~Sv}$ enter via the GreenlandIceland sills and $9.4 \pm 4.7 \mathrm{~Sv}$ enter over the Reykjanes Ridge. Only $-6.2 \pm 4.2 \mathrm{~Sv}$ exit the box across the OVIDE section, thus implying that $3.5 \pm 6.3$ Sv should sink and become part of the lower Irminger box. In this lower Irminger box, 3 Sv enter via the overflow waters and $-6.4 \pm 2.2 \mathrm{~Sv}$ exit across the OVIDE section, thereby $3.4 \pm 2.2 \mathrm{~Sv}$ are missing, and would be those from the upper Irminger box (Fig. 7c). This is in agreement with the mean results for the 2002-2004 OVIDE sections of Lherminier et al. (2010), who estimated that $3.9 \pm 1.8 \mathrm{~Sv}$ cross from the upper to the lower box of the Irminger Basin.

The OMP-based water mass distributions let us disaggregate the water masses that are involved in each of those volume transports. The $1.7 \pm 2.6 \mathrm{~Sv}$ upwelling from the lower to the upper 704 ENA box should be ISOW, since from the $3 \mathrm{~Sv}$ of overflow waters entering the lower ENA box, only $705-1.4 \pm 1.0 \mathrm{~Sv}$ leave the box across the OVIDE section. Thus, the remaining $1.6 \pm 1.0 \mathrm{~Sv}$ should upwell to the upper ENA box, which is proved by the net southward transport of $-0.7 \pm 0.2 \mathrm{~Sv}$ of ISOW in the upper ENA box across the OVIDE section (Fig. 7b). The remaining $0.9 \pm 0.9 \mathrm{SV}$ should cross over the Reykjanes Ridge, which is consistent with the net southward export of $-0.6 \pm$ $0.9 \mathrm{~Sv}$ of ISOW in the Irminger Basin across the OVIDE section.

711 Reykjanes Ridge, we should first determine the composition of the $-7 \mathrm{~Sv}$ crossing the Iceland712 Scotland sills northwards. Since this flow has temperatures over $7^{\circ} \mathrm{C}$ (Schmitz and McCartney, 713 1993; van Aken and Becker, 1996), only the Central Waters, IcSPMW and MW (New et al., 2001) 714 are possible sources. IcSPMW is excluded from this group because it is formed in the Iceland 715 Basin close to the Reykjanes Ridge (McCartney and Talley, 1982; Tsuchiya et al., 1992; van Aken 
716 and Becker, 1996). Considering that the Central Waters and MW account for $11.8 \pm 1.3 \mathrm{~Sv}$ in the

717 ENA Basin across the OVIDE section and that -7 Sv cross the Iceland-Scotland sills northwards,

$7184.8 \pm 1.3 \mathrm{~Sv}$ are available to flow over the Reykjanes Ridge. MW flows northwards through the

719 Rockall trough due to mixing with the Central Waters (Pollard et al., 1996; McCartney and

720 Mauritzen, 2001; New et al., 2001) and does not reach the Reykjanes Ridge, thus the $4.8 \pm 1.3 \mathrm{~Sv}$

721 are attributed to the Central Waters. Once the Central Waters reach the Iceland Basin they

722 transform into IcSPMW (-2.7 $\pm 1.3 \mathrm{~Sv})$, leaving only $2.1 \pm 1.8 \mathrm{~Sv}$ of Central Waters available for

723 crossing over the Reykjanes Ridge. The rest of the flow over the ridge corresponds to those waters

724 colder than $7^{\circ} \mathrm{C}$ entering the upper ENA box through the OVIDE section, i.e., $4.0 \pm 0.5$ Sv of SAIW,

$7252.4 \pm 2.0 \mathrm{~Sv}$ of LSW and the $0.9 \pm 0.9 \mathrm{~Sv}$ of ISOW above estimated. Intensified vertical mixing at

726 the Reykjanes Ridge (Ferron et al., 2014) could explain the appearance and transports of LSW 727 and ISOW over the ridge.

728 After crossing the Reykjanes Ridge, LSW and ISOW intrude in the deep-to-bottom levels of 729 the Irminger Basin, being the main components of the $3.5 \mathrm{~Sv}$ downwelling from the upper to the 730 lower Irminger box. In fact, the net flows of LSW and ISOW in the Irminger Basin are almost 731 compensated by their corresponding flows over the Reykjanes Ridge (Fig. 7b). In the lower 732 Irminger box, the $-2.5 \pm 0.3 \mathrm{~Sv}$ of DSOW leaving this box are slightly lower than the $3 \mathrm{~Sv}$ of 733 overflow waters entering this box. The deficit in the DSOW volume transport, as explained before, 734 is compensated by the excess of LSW and ISOW. This disagreement in the volume transports 735 could be explained by two facts. First, the mixing between IrSPMW and PIW leads to waters with 736 properties similar to those of LSW, which the OMP analysis assigned as LSW. Second, the 737 contributions of the spill jet are very difficult to separate from those of LSW (von Appen et al., 738 2014), so that part of the spill jet that should be contributing to the DSOW volume transport would 739 be attributed to the LSW volume transport.

$740 \quad$ In the upper Irminger box, the transport of PIW across the OVIDE section matches the 1.3 741 Sv entering this box from the Nordic Seas. The remaining water masses present in this box 742 undergo significant transformations. From the $4.0 \pm 0.5 \mathrm{~Sv}$ of SAIW entering the Irminger Basin 743 over the Reykjanes Ridge, $-1.8 \pm 0.3 \mathrm{~Sv}$ exit this basin through the OVIDE section. Besides, 744 considering that $-1 \mathrm{~Sv}$ of Atlantic waters leaves the Irminger Basin towards the Nordic Seas, $3.2 \pm$ 
$7451.8 \mathrm{~Sv}$ of Central Waters and SAIW should have been lost or transformed into other water masses.

746 Considering that IrSPMW derives from IcSPMW, and that the inputs from the latter only account for

$7475.3 \pm 1.2 \mathrm{~Sv}$ in the Irminger Basin (Fig. 7b), the $3.2 \pm 1.8 \mathrm{~Sv}$ of Central Waters and SAIW should 748 have contributed to the IrSPMW volume transport. The net southward export of $-8.8 \pm 0.8 \mathrm{~Sv}$ of 749 IrSPMW across the OVIDE section is most probably the further precursor of LSW in the Labrador 750 Sea (Talley and McCartney, 1982).

751 The high variability of the water mass transports around Cape Farewell (Daniault et al., 752 2011) hinders a consensus on the estimation of the formation of NADW (Clarke, 1984; Dickson 753 and Brown, 1994; Bacon, 1997). The classical study of Dickson and Brown (1994) states that 754 NADW is formed by the merger of ISOW, DSOW, Lower Deep Water (here represented by $755 \mathrm{NEADW}_{\mathrm{L}}$ ) and minor contributions of LSW. Dickson and Brown (1994) state that the ISOW 756 transport would increase due to the contribution of the Lower Deep Water and that LSW would 757 contribute to the increase of the transport of DSOW from the sills until Cape Farewell, which is 758 corroborated in our study by the net southward transport of LSW in the Irminger lower box (Fig. 759 7d). If we add the transports of all the contributors of NADW (net transport of DSOW, ISOW and 760 NEADW $\mathrm{L}_{\mathrm{L}}$ across the OVIDE section, and the net transport of LSW in the Irminger lower box across 761 the OVIDE section), we obtain a production of $9.0 \pm 0.9 \mathrm{~Sv}$, a result slightly lower than the $\sim 10 \mathrm{~Sv}$ 762 reported by Bacon (1997) at Cape Farewell.

763 Although the water mass volume transports given by the water mass distributions are 764 sensitive to the distributions of the SWTs, which are subject to the definition of the SWTs, the 765 volume transports estimated through the water mass distributions are more realistic than those 766 obtained between density layers. In the studies performed between density layers, the volume 767 transports between certain isopycnals are assigned entirely to a water mass, while the 768 methodology described here allows this volume transport to be split between the different water 769 masses found in this density range, which could lead to water mass volume transports lower than 770 those estimated through the isopycnal method.

\section{6. Conclusions}


In this study we show an application of the OMP analysis to identify temporal variations and

773 transformations of the water masses along the WOCE A25 hydrographic sections (southern

774 boundary of the NASPG). Our choice of SWTs and mixing figures is appropriate to describe all the

775 cruise samples, as evidenced by the low residuals of the model. Water mass transformation

776 through air-sea interactions is taken into account in the OMP set-up by specifying several varieties

777 of SPMW. This novelty leads to realistic water mass distributions, confirming generally accepted

778 knowledge of the Subpolar North Atlantic circulation. In particular, our water mass distributions

779 evidence the subduction of SAIW below the NAC and the PIW cascading to the density of the

780 Deep Western Boundary Current. We also provide the relative contribution from each water mass

781 to the transports across the sections by combining the results from the OMP analysis with the

782 velocity fields of the sections. The assessment of the water mass volume transports based on

783 dilutions of a "pure" SWT (OMP-based) is particularly useful for areas of complex currents and

784 relevant processes of water mass transformation, where this combined methodology can provide 785 robust insights on the circulation features, improving the understanding of the regional 786 oceanography.

787 The transport estimates by water mass are in good agreement with previous studies and 788 match the main features of the northern North Atlantic Circulation. Considering the isopycnal that 789 separates the upper and lower limbs of the AMOC $\left(\sigma_{1}=32.15\right)$, we associate each SWT with the 790 corresponding AMOC limb. In our study, the upper limb of the AMOC is represented by the Central 791 Waters, IcSPMW, SAIW and MW; and the lower limb of the AMOC is constituted by IrSPMW, PIW, 792 LSW, ISOW, DSOW and NEADW . This allows us to associate the reduction of the magnitude of 793 the upper limb of the AMOC between 1997 and the 2000s (from $23.3 \pm 1.2$ Sv to $16.5 \pm 1.5 \mathrm{~Sv}$ ) 794 with the reduction in the northward transport of the Central Waters. This reduction of the northward 795 flow of the upper limb of the AMOC is partially compensated by the reduction of the southward flow 796 of the lower limb of the AMOC, associated with the decrease in the transports of IrSPMW and PIW. 797 The assessment of the box budgets allows us to disentangle the transformation pathway of 798 the Central Waters. In the ENA Basin, 2.7 Sv of Central Waters are transformed into IcSPMW. This 799 flow recirculates around the Reykjanes Ridge and joins IcSPMW advected from the south (possibly 800 through a branch of the NAC as suggested by Pollard et al. (2004)), leading to a northward 
801 transport of $5.3 \mathrm{~Sv}$ of IcSPMW in the Irminger Sea. These 5.3 Sv combine with $1.1 \mathrm{~Sv}$ of Central 802 Waters and 2.2 Sv of SAIW (crossing over the Reykjanes Ridge) to give 8.8 Sv of IrSPMW through 803 air-sea interaction.

804 LSW is the main water mass across the sections ( $35.0 \pm 0.6 \%$ of the section volume). The 805 inter-annual variability observed in the upper layers of the Irminger Basin reflects the interplay 806 between LSW and SPMW, the mixing of which emulates the presence of the upper LSW. In the 807 lower layers at both sides of the Reykjanes Ridge it is possible to notice an interaction between 808 LSW and ISOW, with an increasing presence of ISOW responding to the progressive dilution of 809 LSW. The OMP results also reveal that LSW is strongly mixed with the surrounding waters mainly 810 in two regions: (i) at and upstream of the Reykjanes Ridge, and (ii) in the Deep Western Boundary 811 Current, where the contribution of LSW is significant $\left(\sigma_{0}>27.80\right)$. The slightly negative net 812 transport of LSW across the OVIDE section is in agreement with a moderate formation of LSW in 813 the Irminger Basin.

814 Waters from the ENA Basin cross over the Reykjanes Ridge and enter the Irminger Basin, 815 where they are transformed and/or densified, passing from the upper and intermediate water 816 domains to the deep water domain. The OMP analysis allowed us to decompose the $9.4 \mathrm{~Sv}$ of flow 817 across the Reykjanes Ridge into Central Waters, SAIW, LSW and ISOW; SAIW being the main 818 contributor.

819 The distributions and transports of ISOW allow us to infer that in the course of the ISOW'S 820 journey from the Iceland-Scotland sills to the CGFZ, part of it upwells and flows through gaps in 821 the Reykjanes Ridge between the OVIDE and 4x sections. Once ISOW arrives at the CGFZ some 822 fractions continue to flow into the West European Basin while the main stream crosses the fracture 823 to the Irminger Basin, flowing northwards and joining the fractions that previously crossed the 824 ridge.

825 The extension of this methodology to wide areas of the ocean could provide a useful basis 826 for this kind of study or more ambitious ones dealing with the cycle of biogeochemical components 827 in the ocean. 


\section{Acknowledgements}

829 We are grateful to the captains, staff and researchers who contributed to the acquisition 830 and data processing. The research leading to these results was supported through the EU FP7

831 project CARBOCHANGE, which received funding from the European Commission's Seventh 832 Framework Programme under grant agreement no. 264879. For this work M.I. García-lbáñez was 833 supported by the Spanish Ministry of Economy and Competitiveness (BES-2011-045614) through 834 the CATARINA (CTM2010-17141) and BOCATS projects (CTM2013-41048-P) supported by the 835 Spanish Government and co-funded by the Fondo Europeo de Desarrollo Regional 2007-2012 836 (FEDER); and this article is going to be part of her PhD that is attached to the framework of the 837 doctoral program "Marine Science, Technology and Management" (DO*MAR) of the University of 838 Vigo. P.C. Pardo, L.I. Carracedo, A.F. Rios and F.F. Pérez were supported by the Spanish 839 National Research Council (CSIC); H. Mercier by the French National Centre for Scientific 840 Research (CNRS); and P. Lherminier by the French Institute for Marine Science (Ifremer). 
841

842

843

844

845

846

847

848

849

850

851

852

853

854

855

856

857

858

859

860

861

862

863

864

865

\section{Appendix}

\section{A1. Specifications of the OMP analysis}

The Optimum MultiParameter (OMP) analyses consider the properties (physical and/or chemical) of a given water sample to be the result of linear combinations of a finite number of water masses represented by the so-called Source Water Types (SWT). They compute the fractions of each SWT $\left(X_{i}\right)$ in each water sample. In the OMP analyses, the SWT properties are assumed to be independent and equally affected by mixing. In addition, SWTs are considered to be time invariant; hence, changes in the properties of the water masses over time are reflected through water mass redistributions.

The methodology of the analysis applied in this work consists of two OMP steps. In the first step a classical OMP (cOMP) is solved for each water sample. The cOMP analysis is based on conservative variables; in particular, in this study we used $\theta, \mathrm{S}, \mathrm{SiO}_{2}$, "NO" and "PO" (where "NO" = $10.5 * \mathrm{NO}_{3}+\mathrm{O}_{2}$, "PO" $=175 * \mathrm{PO}_{4}+\mathrm{O}_{2}$; Broecker, 1974; Takahashi et al., 1985; Anderson and Sarmiento, 1994):

$$
\begin{gathered}
\sum_{\mathrm{i}=1}^{\mathrm{n}} \mathrm{X}_{\mathrm{i}} * \theta_{\mathrm{i}}^{\mathrm{SWT}}=\theta^{\text {sample }}+\mathrm{R}_{\theta} \\
\sum_{\mathrm{i}=1}^{\mathrm{n}} \mathrm{X}_{\mathrm{i}} * \mathrm{~S}_{\mathrm{i}}^{\mathrm{SWT}}=\mathrm{S}^{\text {sample }}+\mathrm{R}_{\mathrm{S}} \\
\sum_{\mathrm{i}=1}^{\mathrm{n}} \mathrm{X}_{\mathrm{i}} * \mathrm{SiO}_{2 \mathrm{i}}^{\text {SWT }}=\mathrm{SiO}_{2}^{\text {sample }}+\mathrm{R}_{\mathrm{SiO}_{2}} \\
\sum_{\mathrm{i}=1}^{\mathrm{n}} \mathrm{X}_{\mathrm{i}} * \mathrm{NO}_{\mathrm{i}}^{\mathrm{SWT}}=\mathrm{NO}^{\text {sample }}+\mathrm{R}_{\mathrm{NO}} \\
\sum_{\mathrm{i}=1}^{\mathrm{n}} \mathrm{X}_{\mathrm{i}} * \mathrm{PO}_{\mathrm{i}}^{\mathrm{SWT}}=\mathrm{PO}^{\text {sample }}+\mathrm{R}_{\mathrm{PO}} \\
\sum_{\mathrm{i}=1}^{\mathrm{n}} \mathrm{X}_{\mathrm{i}}=1+\mathrm{R}_{\text {mass }}
\end{gathered}
$$

where $\mathrm{R}_{\mathrm{p}}$ is the residual of each property $\mathrm{p}\left(\theta, \mathrm{S}, \mathrm{SiO}_{2}, \mathrm{NO}\right.$ and $\mathrm{PO}$ ) measured ( $\mathrm{p}^{\text {sample }}$ ) that the OMP tries to minimize and $p_{i}^{S W T}$ is the property of each SWT $i$. The last equation accounts for the mass conservation. Before solving the system (minimization through a non-negative least square method), the equations are normalized (Tomczak and Large, 1989) and weighted (Pardo et al., 2012) (Table 2). The assignment of weights was, as a first step, directly related to the accuracy of the property and/or to the variability in the region of study. Weights were also adjusted so that the ratios between the Standard Deviations of the Residuals and the analytical error $(\varepsilon$, accuracy of the measured properties) were almost the same for all the SWT properties (Table 2). The weights of $\theta$ and $S$ are higher than those of the other properties because both have the lowest $\varepsilon$. The mass equation has the highest weight to ensure its conservation. 
that are susceptible to mix together, and are set considering the vertical characteristics and/or dynamics of the SWTs in the region of study. Each mixing figure is constituted by a maximum of four SWTs in order to solve the system of 6 equations with at least two degrees of freedom (Eq. A1.1). The mixing figures are vertically and horizontally sequenced, sharing at least one SWT with

871 the adjacent mixing figures. The cOMP analysis is applied to assign the mixing figure where the water sample is best included (lowest residuals).

874 the cOMP except that the eOMP considers conservative and non-conservative variables. We used $\theta$ and $\mathrm{S}$ as conservative variables and $\mathrm{SiO}_{2}, \mathrm{NO}_{3}, \mathrm{PO}_{4}$ and $\mathrm{O}_{2}$ as non-conservative variables. $\mathrm{A}$ new unknown has to be considered, $\Delta O$, in order to account for the biogeochemical process of remineralisation of the organic matter. The system of equations remains as follows:

$$
\begin{gathered}
\sum_{\mathrm{i}=1}^{\mathrm{n}} \mathrm{X}_{\mathrm{i}} * \theta_{\mathrm{i}}^{\mathrm{SWT}}=\theta^{\text {sample }}+\mathrm{R}_{\theta} \\
\sum_{\mathrm{i}=1}^{\mathrm{n}} \mathrm{X}_{\mathrm{i}} * \mathrm{~S}_{\mathrm{i}}^{\mathrm{SWT}}=\mathrm{S}^{\text {sample }}+\mathrm{R}_{\mathrm{S}} \\
\sum_{\mathrm{i}=1}^{\mathrm{n}} \mathrm{X}_{\mathrm{i}} * S i O_{2}{ }_{i}^{S W T}+\Delta \mathrm{O} / \mathrm{r}_{\mathrm{Si}}=\mathrm{SiO}_{2}{ }^{\text {sample }}+\mathrm{R}_{\mathrm{SiO}_{2}} \\
\sum_{\mathrm{i}=1}^{\mathrm{n}} \mathrm{X}_{\mathrm{i}} * O_{2}^{0}{ }_{i}^{S W T}-\Delta \mathrm{O}=\mathrm{O}_{2}{ }^{\text {sample }}+\mathrm{R}_{\mathrm{O}_{2}} \\
\sum_{\mathrm{i}=1}^{\mathrm{n}} \mathrm{X}_{\mathrm{i}} * N O_{3_{i}^{0}}^{S W T}+\Delta \mathrm{O} / \mathrm{r}_{\mathrm{N}}=\mathrm{NO}_{3}{ }^{\text {sample }}+\mathrm{R}_{\mathrm{NO}_{3}} \\
\sum_{\mathrm{i}=1}^{\mathrm{n}} \mathrm{X}_{\mathrm{i}} * P O_{4}^{0^{S W T}}+\Delta \mathrm{O} / \mathrm{r}_{\mathrm{P}}=\mathrm{PO}_{4}{ }^{\text {sample }}+\mathrm{R}_{\mathrm{PO}_{4}} \\
\sum_{\mathrm{i}=1}^{\mathrm{n}} \mathrm{X}_{\mathrm{i}}=1+\mathrm{R}_{\text {mass }}
\end{gathered}
$$

where $r_{\mathrm{Si}}$ is $12, r_{\mathrm{N}}$ is 10.5 and $r_{\mathrm{P}}$ is 175 (Takahashi et al., 1985; Anderson and Sarmiento, 1994).

The final result from the eOMP analysis is the $X_{i} s$ in each water sample in the corresponding mixing figure selected through the cOMP analysis.

The cOMP analysis selects the mixing figure based on conservative water mass tracers, avoiding the complexity added by the non-conservative variables. Even though this analysis does not consider the variability associated with biological processes, it is accurate enough to select the appropriate mixing figure. Once the mixing figures are selected, the estimates of the $X_{i} \mathrm{~s}$ are given by the eOMP analysis, which does take into account the effect of the biology in the measured variables. 


\section{A2. Testing the robustness: perturbation analysis of uncertainties}

The robustness of the OMP analysis was tested through a perturbation analysis of uncertainties (Lawson and Hanson, 1974). In this work, the properties of both each SWT and each water sample were perturbed. This allowed us to check the sensitivity of the model to variations in the SWTs, due to environmental variability, and in the water samples, due to measurement errors (Leffanue and Tomczak, 2004).

To apply this procedure, it is assumed that the property distributions follow a normal distribution constructed with the mean equal to the property value at each point and a standard deviation (STD) (Álvarez et al., 2004; Pardo et al., 2012). The perturbation process lies in varying the property values within the normal distribution. All the STDs used in perturbing the SWTs are shown in Table 2.

The STDs of the water sample properties ( $\varepsilon$ in Table 2$)$ were obtained by considering $\varepsilon$ almost equal to the accuracy of each water sample property $\left(\varepsilon_{\theta} 0.01, \varepsilon_{S} 0.01, \varepsilon_{\mathrm{SiO}_{2}} 0.3, \varepsilon_{\mathrm{NO}_{3}} 0.2\right.$, $\varepsilon_{P_{4}} 0.02$ and $\varepsilon_{O_{2}}$ 1). The STDs of the properties of the SWTs were obtained within the realm of the $\operatorname{SWT}\left(X_{i}>75-95 \%\right)$ by one of the following methods:

a) Following Karstensen and Tomczak (1998), the water samples with more than $95 \%$ of contribution of a certain SWT $\left(X_{i}\right)$ were selected and the STD calculated for each property. This method was only used when the number of water samples that could be selected for a certain SWT was more than 50 . This procedure was applied to LSW, ISOW and NEADW .

b) For the water masses that were modelled by various SWTs (multi-SWTs), as the Central Waters, DSOW and SPMW, the multi-SWT contributions were obtained by adding the contributions of their respective components. Then the water samples with $X_{i}$ of the multiSWT greater than $95 \%$ were selected. The property values of each component of the multiSWT were then subtracted from the values of the water samples and linear regressions between $\theta$ and the rest of the resulting properties were performed. The STDs of the multiSWT properties were assumed to be equal to the error of the intercept. The properties of each component of the multi-SWT had the same STDs as the corresponding ones in the multi-SWT. With this methodology the variability due to the $\theta$ variability was removed. 
c) A modification of the methodology in (b) was applied to MW, where samples with $X_{i}>75 \%$ were selected and used for the linear regressions.

The STDs of the properties of SAIW were assigned equal to those of the Central Waters, because not enough water samples presented $X_{i}>95 \%$ of this water mass. The STD of NEADW was computed using the errors of the SWTs in which it is assumed to decompose (section 3).

We set the STDs for the $\mathrm{O}_{2}$ as a value equal to $3 \%$ of the saturation value, since when a

923 water mass is formed the content of $\mathrm{O}_{2}$ is not exactly the saturation value (Najjar and Keeling, 924 2000; Ito et al., 2004).

100 perturbations were performed and the OMP analysis was solved for each perturbed system. Uncertainties in the $X_{i} \mathrm{~s}$ are computed from the results of the perturbations. We calculated 927 the STD of the 100 SWT distribution matrixes. The mean of the STD matrix is shown in Table 2. 928 The SWTs with higher mean STD values are those that belong to a mixing figure that covers a 929 small property range, where the variability of the SWTs has a greater effect.

\section{A3. Testing the accuracy: residuals}

The least square method constrained to non-negative solutions returns the total residual, i.e., the squared largest singular value for the set of residuals resulting from the eOMP equation system (section A1). These residuals give insights about the reliability of the proposed mixing model, and indicate the quality of the solution for each depth range. The total and individual residuals for the water samples are shown in Fig. A3.1.

The total residual of the eOMP analysis is almost zero from $500 \mathrm{~m}$ depth to the bottom (Fig.

938 the assumption of conservativeness is not justified because this layer is subject to seasonal 939 variability. Nevertheless, as $\theta$ and $S$ have the highest weights in the analysis (Table 2), the 940 majority of the positive residuals of $\theta$ in the surface-subsurface layer are compensated by the 941 corresponding negative residuals of S. 
944 (Table 2). The Standard Deviations of the Residuals provide an estimation of the goodness of our 945 proposed mixing model. 
946

947

948

949

950

951

952

953

954

955

956

957

958

959

960

961

962

963

964

965

966

967

968

969

970

971

972

973

\section{References}

Álvarez, M., Bryden, H.L., Pérez, F.F., Ríos, A.F., Rosón, G., 2002. Physical and biogeochemical fluxes and net budgets in the subpolar and temperate North Atlantic. Journal of Marine Research 60, 191-226. doi: 10.1357/00222400260497462.

Álvarez, M., Brea, S., Mercier, H., Álvarez-Salgado, X.A., 2014. Mineralization of biogenic materials in the water masses of the South Atlantic Ocean. I: Assessment and results of an optimum multiparameter analysis. Progress in Oceanography 123, 1-23. doi: 10.1016/j.pocean.2013.12.007.

Álvarez, M., Pérez, F.F., Bryden, H., Ríos, A.F., 2004. Physical and biogeochemical transports structure in the North Atlantic subpolar gyre. Journal of Geophysical Research 109, C03027. doi: 10.1029/2003JC002015.

Ambar, I., Howe, M.R., 1979. Observations of the Mediterranean outflow-I: Mixing in the Mediterranean outflow. Deep Sea Research Part A. Oceanographic Research Papers 26, 5, 535-554. doi: 10.1016/0198-0149(79)90095-5.

Aminot, A., Chaussepied, M., 1983. Manuel des analyses chimiques en Milieu Marin. Publications du CNEXO, 395p.

Anderson, L.A., Sarmiento, J.L., 1994. Redfield ratios of remineralization determined by nutrient data analysis. Global Biogeochemical Cycles 8, 1, 65-80. doi: 10.1029/93GB03318.

Arhan, M., 1990. The North Atlantic Current and subarctic intermediate water. Journal of Marine Research 48, 1, 109-144. doi: 10.1357/002224090784984605.

Arhan, M., Colin de Verdière, A., Mémery, L., 1994. The eastern boundary of the subtropical North Atlantic. Journal of Physical Oceanography 24, 6, 1295-1316. doi: 10.1175/15200485(1994)024<1295:TEBOTS>2.0.CO;2.

Arhan, M., King, B., 1995. Lateral mixing of the Mediterranean Water in the eastern North Atlantic. Journal of Marine Research 53, 6, 865-895. doi: 10.1357/0022240953212990.

Bacon, S., 1997. Circulation and Fluxes in the North Atlantic between Greenland and Ireland. Journal of Physical Oceanography 27, 1420-1435. doi: 10.1175/15200485(1997)027<1420:CAFITN>2.0.CO;2. 
974 Balmaseda, M.A., Smith, G.C., Haines, K., Anderson, D., Palmer, T.N., Vidard, A., 2007. Historical reconstruction of the Atlantic Meridional Overturning Circulation from the ECMWF operational ocean reanalysis. Geophysical Research Letters 34, L23615. doi: 10.1029/2007GL031645.

978 Baringer, M.O., Price, J.F., 1997. Mixing and Spreading of the Mediterranean Outflow. Journal of Physical Oceanography 27, 8, 1654-1677. doi: 10.1175/15200485(1997)027<1654:MASOTM>2.0.CO;2.

Bersch, M., 2002. North Atlantic Oscillation-induced changes of the upper layer circulation in the northern North Atlantic Ocean. Journal of Geophysical Research 107, C10, 3156. doi: 10.1029/2001JC000901.

Bersch, M., Meincke, J., Sy, A., 1999. Interannual thermohaline changes in the northern North Atlantic 1991-1996. Deep Sea Research Part II: Topical Studies in Oceanography 46, (1-2), 55-75. doi: 10.1016/S0967-0645(98)00114-3.

Bersch, M., Yashayaev, I., Koltermann, K.P., 2007. Recent changes of the thermohaline circulation in the subpolar North Atlantic. Ocean Dynamics 57, 3, 223-235. doi: 10.1007/s10236-0070104-7.

Böning, C.W., Bryan, F.O., Holland, W.R., Döscher, R., 1996. Deep-Water Formation and Meridional Overturning in a High-Resolution Model of the North Atlantic. Journal of Physical $\begin{array}{lll}\text { Oceanography } & 26, & 1142-1164.1175 / 1520\end{array}$ 0485(1996)026<1142:DWFAMO>2.0.CO;2.

Böning, C.W., Scheinert, M., Dengg, J., Biastoch, A., Funk, A., 2006. Decadal variability of subpolar gyre transport and its reverberation in the North Atlantic overturning. Geophysical Research Letters 33, L21S01. doi: 10.1029/2006GL026906.

Branellec, P., Thierry V., 2013. OVIDE $2010 \quad$ CTD-O ${ }_{2}$ cruise report. http://archimer.ifremer.fr/doc/00210/32134.

Brambilla, E., Talley, L.D., 2008. Subpolar Mode Water in the northeastern Atlantic: 1. Averaged properties and mean circulation. Journal of Geophysical Research 113, C04025. doi: 10.1029/2006JC004062. 
1002 Brambilla, E., Talley, L.D., Robbins, P.E., 2008. Subpolar Mode Water in the northeastern Atlantic:

1003

1004

1005

1006

1007

1008

1009

1010

1011

1012

1013

1014

1015

1016

1017

1018

1019

1020

1021

1022

1023

1024

1025

1026

1027

1028

1029

2. Origin and transformation. Journal of Geophysical Research 113, C4, C04026. doi: 10.1029/2006JC004063

Broecker, W.S., 1974. "NO", a conservative water-mass tracer. Earth and Planetary Science Letters 23, 1, 100-107. doi: 10.1016/0012-821X(74)90036-3.

Bryden, H.L., King, B.A., McCarthy, G.D., McDonagh, E.L., 2014. Impact of a 30\% reduction in Atlantic meridional overturning during 2009-2010. Ocean Science 10, 683-691. doi: 10.5194/os-10-683-2014.

Bubnov, V.A., 1968. Intermediate subarctic waters in the northern part of the Atlantic Ocean. Okeanologia 19, 136-153 (English translation, N00 Trnas 545, U.S. Nav. Oceanogr. Off., Washington, D. C., 1973).

Carracedo, L.I., Gilcoto, M., Mercier, H., Pérez, F.F., 2014. Seasonal dynamics in the AzoresGibraltar Strait region: A climatologically-based study. Progress in Oceanography 122, 116130. doi: 10.1016/j.pocean.2013.12.005.

Carracedo, L.I., Pardo, P.C., Villacieros-Robineau, N., De la Granda, F., Gilcoto, M., Pérez, F.F., 2012. Temporal changes in the water mass distribution and transports along the $20^{\circ} \mathrm{W}$ CAIBOX section (NE Atlantic). Ciencias Marinas 38, 1B, 263-286. doi: 10.7773/cm.v38i1B.1793.

Castro, C.G., Pérez, F.F., Holley, S.E., Ríos, A.F., 1998. Chemical characterisation and modelling of water masses in the Northeast Atlantic. Progress in Oceanography 41, 249-279. doi: 10.1016/S0079-6611(98)00021-4

Clarke, R.A., 1984. Transport through the Cape Farewell-Flemish Cap section. Rapp. PV Reun. Cons. Int. Explor. Mer, 185, 120-130.

Culberson, C.H., 1991. WOCE operations manual (WHP operations and methods), WHPO 91/1. Woods Hole Oceanogr. Inst., Woods Hole, Mass.

Cunningham, S.A., Haine, T.W.N., 1995. Labrador Sea Water in the eastern North Atlantic. Part II: Mixing dynamics and the advective-diffusive balance. Journal of Physical Oceanography 14, 103-127. doi: 10.1175/1520-0485(1995)025<0666:LSWITE>2.0.CO;2. 
1030 Curry, R.G., McCartney, M.S., 2001. Ocean Gyre Circulation Changes Associated with the North Atlantic Oscillation*. Journal of Physical Oceanography 31, 3374-3400. doi: 10.1175/15200485(2001)031<3374:OGCCAW>2.0.CO;2.

Daniault, N., Lherminier, P., Mercier, H., 2011. Circulation and transport at the southeast tip of Greenland. Journal of Physical Oceanography 41, 3, 437-457. doi: 10.1175/2010JPO4428.1.

de Boisséson, E., Thierry, V., Mercier, H., Caniaux, G., Desbruyères, D., 2012. Origin, formation and variability of the Subpolar Mode Water located over the Reykjanes Ridge. Journal of Geophysical Research 117, C12005. doi: 10.1029/2011JC007519.

1039 de Jong, M.F., van Aken, H.M., Våge, K., Pickart, R.S., 2012. Convective mixing in the central 1040 Irminger Sea: 2002-2010. Deep Sea Research Part I: Oceanographic Research Papers 63, $1041 \quad 36-51$. doi: 10.1016/j.dsr.2012.01.003.

1042 Dengler, M., Fischer, J., Schott, F.A., Zantopp R., 2006. Deep Labrador Current and its variability 1043 in 1996-2005. Geophys. Research Letters 33, L21S06. doi: 10.1029/2006GL026702.

1044 Desbruyères, D., Thierry, V., Mercier, H., 2013. Simulated decadal variability of the meridional 1045 overturning circulation across the A25-Ovide section. Journal of Geophysical Research 1046 Oceans 118, 462-475. doi: 10.1029/2012JC008342.

1047 Dickson, B., Yashayaev, I., Meincke, J., Turrell, B., Dye, S., Holfort, J., 2002. Rapid freshening of 1048 the deep North Atlantic Ocean over the past four decades. Nature 416, 6883, 832-837. doi: $1049 \quad 10.1038 / 416832 a$.

1050 Dickson, R., Lazier, J., Meincke, J., Rhines, P., Swift, J., 1996. Long-term coordinated changes in 1051 the convective activity of the North Atlantic. Progress in Oceanography 38, 3, 241-295. doi: $1052 \quad 10.1016 /$ S0079-6611(97)00002-5.

1053 Dickson, R.R., Brown, J., 1994. The production of North Atlantic Deep Water: sources, rates, and 1054 pathways. Journal of Geophysical Research 99, C6, 12319-12. doi: 10.1029/94JC00530.

1055 Eden, C., Willebrand, J., 2001. Mechanism of Interannual to Decadal Variability of the North 1056 Atlantic Circulation. Journal of Climate 14, 2266-2280. doi: 10.1175/15201057 0442(2001)014<2266:MOITDV>2.0.CO;2. 
1058 Falina, A., Sarafanov, A., Mercier, H., Lherminier, P., Sokov, A., Daniault, N., 2012. On the Cascading of Dense Shelf Waters in the Irminger Sea. Journal of Physical Oceanography 42, 2254-2267. doi: 10.1175/JPO-D-12-012.1.

1061 Ferron, B., Kokoszka, F., Mercier, H., Lherminier, P., 2014. Dissipation rate estimates from microstructure and finescale internal wave observations along the A25 Greenland-Portugal OVIDE line. Journal of Atmospheric and Oceanic Technology 31, 2530-2543. doi: 10.1175/JTECH-D-14-00036.1.

Flatau, M.K., Talley, L., Niiler, P.P., 2003. The North Atlantic Oscillation, Surface Current Velocities, and SST Changes in the Subpolar North Atlantic. Journal of Climate 16, 23552369. doi: $10.1175 / 2787.1$.

Fogelqvist, E., Blindheim, J., Tanhua, T., Østerhus, S., Buch, E., Rey, F., 2003. GreenlandScotland overflow studied by hydro-chemical multivariate analysis. Deep Sea Research Part I: Oceanographic Research Papers 50, 1, 73-102. doi: 10.1016/S09670637(02)00131-0.

Gourcuff, C., Lherminier, P., Mercier, H., Le Traon, P.Y., 2011. Altimetry Combined with Hydrography for Ocean Transport Estimation. Journal of Atmospheric and Oceanic Technology 28, 10, 1324-1337. doi: 10.1175/2011JTECHO818.1.

Häkkinen, S., Rhines, P.B., 2004. Decline of subpolar North Atlantic circulation during the 1990s. Science 304, 5670, 555-559. doi: 10.1126/science.1094917.

Hansen, B., Österhus, S., 2000. North Atlantic-nordic seas exchanges. Progress in Oceanography 45, 2, 109-208. doi: 10.1016/S0079-6611(99)00052-X.

Harvey, J., 1982. Theta-S relationships and water masses in the eastern North Atlantic. Deep Sea Research Part A. Oceanographic Research Papers 29, 8, 1021-1033. doi: 10.1016/01980149(82)90025-5.

Harvey, J., Arhan, M., 1988. The water masses of the central North Atlantic in 1983-84. Journal of Physical Oceanography 18, 12, 1855-1875. doi: 10.1175/15200485(1988)018<1855:TWMOTC>2.0.CO;2. 
1085 Hátún, H., Sandø, A.B., Drange, H., Hansen, B., Valdimarsson, H., 2005. Influence of the Atlantic subpolar gyre on the thermohaline circulation. Science 309, 5742, 1841-1844. doi: 10.1126/science.1114777.

Hurrell, J.W., 1995. Decadal Trends in the North Atlantic Oscillation: Regional Temperatures and Precipitation. Science 269, 676-679. doi: 10.1126/science.269.5224.676.

Iselin, C.O., 1936. A study of the circulation of the western North Atlantic. Pap. Phys. Oceanogr. Meteorol. Massachusetts Inst. Tech. and Woods Hole Oceanographic Inst. 101p.

Ito, T., Follows, M.J., Boyle, E.A., 2004. Is AOU a good measure of respiration in the oceans? Geophysical research letters 31, L17305. doi: 10.1029/2004GL020900.

Jochumsen, K., Quadfasel, D., Valdimarsson, H., Jónsson S., 2012. Variability of the Denmark Strait overflow: Moored time series from 1996-2011. Journal of Geophysical Research 117, C12003, doi: 10.1029/2012JC008244.

Josey, S.A., Grist, J.P., Marsh, R., 2009. Estimates of meridional overturning circulation variability in the North Atlantic from surface density flux fields. Journal of Geophysical Research 114, C09022. doi: 10.1029/2008JC005230.

Karstensen, J., Tomczak, M., 1998. Age determination of mixed water masses using CFC and oxygen data. Journal of Geophysical Research 103, C9, 18599-18609. doi:

1103 Kieke, D., Rhein, M., Stramma, L., Smethie, W.M., Bullister, J.L., LeBel, D.A., 2007. Changes in 1104

1108 Lawson, C.L., Hanson, R.J., 1974. Solving least squares problems. Society for Industrial and $1109 \quad$ Applied Mathematics (SIAM). 351p.

1110 Lazier, J., Hendry, R., Clarke, A., Yashayaev, I., Rhines, P., 2002. Convection and restratification 1111 in the Labrador Sea, 1990-2000. Deep Sea Research Part I: Oceanographic Research 1112 Papers 49, 10, 1819-1835. doi: 10.1016/S0967-0637(02)00064-X. 
1113 Lazier, J.R.N., 1973. The renewal of Labrador Sea Water. Deep Sea Research and 1114 Oceanographic Abstracts 20, 4, 341-353. doi: 10.1016/0011-7471(73)90058-2.

1115 Leffanue, H., Tomczak, M., 2004. Using OMP analysis to observe temporal variability in water mass distribution. Journal of marine systems 48, 1, 3-14. doi: 10.1016/j.jmarsys.2003.07.004.

1118 Lherminier, P., Mercier, H., Gourcuff, C., Alvarez, M., Bacon, S., Kermabon, C., 2007. Transports across the 2002 Greenland-Portugal Ovide section and comparison with 1997. Journal of

1121 Lherminier, P., Mercier, H., Huck, T., Gourcuff, C., Perez, F.F., Morin, P., Sarafanov, A., Falina, A., 2010. The Atlantic Meridional Overturning Circulation and the subpolar gyre observed at the A25-OVIDE section in June 2002 and 2004. Deep Sea Research Part I: Oceanographic Research Papers 57, 11, 1374-1391. doi: 10.1016/j.dsr.2010.07.009.

Mackas, D.L., Denman, K.L., Bennett, A.F., 1987. Least squares multiple tracer analysis of water mass composition. Journal of Geophysical Research 92, C3, 2907-2918. doi: 10.1029/JC092iC03p02907.

Macrander, A., Send, U., Valdimarsson, H., Jónsson, S., Käse, R.H., 2005. Interannual changes in the overflow from the Nordic Seas into the Atlantic Ocean through Denmark Strait. Geophysical Research Letters 32, 6, L06606. doi: 10.1029/2004GL021463.

Malmberg, S.A., 1972. Intermediate Polar Water in the Denmark Strait Overflow August 1971. ICES Conf. Meet. 6, 44-60.

Mantyla, A.W., 1994. The treatment of inconsistencies in Atlantic deep water salinity data. Deep Sea Research Part I: Oceanographic Research Papers 41, 9, 1387-1405. doi: 10.1016/0967-0637(94)90104-X.

1136 Marsh, R., de Cuevas, B.A., Coward, A.C., Bryden, H.L., Álvarez, M., 2005. Thermohaline circulation at three key sections in the North Atlantic over 1985-2002. Geophysical Research Letters 32, L10604. doi: 10.1029/2004GL022281.

Mazé, J.P., Arhan, M., Mercier, H., 1997. Volume budget of the eastern boundary layer off the Iberian Peninsula. Deep Sea Research Part I: Oceanographic Research Papers 44, 9-10, 1543-1574. doi: 10.1016/S0967-0637(97)00038-1. 
1142 McCartney, M.S., Mauritzen, C., 2001. On the origin of the warm inflow to the Nordic Seas. 1143 Progress in Oceanography 51, 1, 125-214. doi: 10.1016/S0079-6611(01)00084-2.

1144 McCartney, M.S., Talley, L.D., 1982. The subpolar mode water of the North Atlantic Ocean. 1145 Journal of Physical Oceanography 12, 11, 1169-1188. doi: 10.1175/15200485(1982)012<1169:TSMWOT>2.0.CO;2.

1147 Mercier, H., 1986. Determining the general circulation of the ocean: A nonlinear inverse problem. Journal of Geophysical Research 91, C4, 5103-5109. doi: 10.1029/JC091iC04p05103.

1149 Mercier, H., Lherminier, P., Sarafanov, A., Gaillard, F., Daniault, N., Desbruyères, D., Falina, A., Ferron, B., Gourcuff, C., Huck, T., 2015. Variability of the meridional overturning circulation at the Greenland-Portugal OVIDE section from 1993 to 2010. Progress in Oceanography

Najjar, R.G., Keeling, R.F., 2000. Mean annual cycle of the air-sea oxygen flux: A global view. Global Biogeochemical Cycles 14, 2, 573-584. doi: 10.1029/1999GB900086.

1155 New, A.L., Barnard, S., Herrmann, P., Molines, J.-M., 2001. On the origin and pathway of the saline inflow to the Nordic Seas: insights from models. Progress in Oceanography 48, 2-3, 255-287. doi: 10.1016/S0079-6611(01)00007-6.

1158 Olsen, S.M., Hansen, B., Quadfasel, D., Østerhus, S., 2008. Observed and modelled stability of overflow across the Greenland-Scotland ridge. Nature 455, 519-522. doi: 10.1038/nature07302.

1161 Olsson, K.A., Jeansson, E., Tanhua, T., Gascard, J.-C., 2005. The East Greenland Current studied with CFCs and released sulphur hexafluoride. Journal of Marine Systems 55, 1, 77-95. doi:

1164 Paillet, J., Arhan, M., McCartney, M.S., 1998. Spreading of Labrador Sea Water in the eastern 1165 North Atlantic. Journal of Geophysical Research 103, C5, 10223-10239. doi: 10.1029/98JC00262.

1167 Pardo, P.C., Pérez, F.F., Velo, A., Gilcoto, M., 2012. Water masses distribution in the Southern 1168 Ocean: Improvement of an extended OMP (eOMP) analysis. Progress in Oceanography 103, 92-105. doi: 10.1016/j.pocean.2012.06.002. 
1170 Pérez, F.F., Mercier, H., Vázquez-Rodríguez, M., Lherminier, P., Velo, A., Pardo, P.C., Rosón, G., 1171 Ríos, A.F., 2013. Atlantic Ocean $\mathrm{CO}_{2}$ uptake reduced by weakening of the meridional overturning circulation. Nature Geoscience 6, 2, 146-152. doi: 10.1038/ngeo1680.

1173 Pickart, R.S., 1992. Water mass components of the North Atlantic deep western boundary current. Deep Sea Research Part A. Oceanographic Research Papers 39, 9, 1553-1572. doi: 10.1016/0198-0149(92)90047-W.

Pickart, R.S., Smethie Jr., W.M., Lazier, J.R.N., Jones, E.P., Jenkins, W.J., 1996. Eddies of newly formed upper Labrador Sea water. Journal of Geophysical Research 101, C9, 2071120726. doi: 10.1029/96JC01453.

Pickart, R.S., Straneo, F., Moore, G.K., 2003. Is Labrador Sea Water formed in the Irminger basin? Deep Sea Research Part I: Oceanographic Research Papers 50, 1, 23-52. doi: 10.1016/S0967-0637(02)00134-6.

Pickart, R.S., Torres, D.J., Fratantoni, P.S., 2005. The East Greenland Spill Jet. Journal of Physical Oceanography 35, 1037-1053. doi: 10.1175/JPO2734.1.

1184 Pollard, R.T., Grifftths, M.J., Cunningham, S.A., Read, J.F., Pérez, F.F., Ríos, A.F., 1996. Vivaldi 1991 - A study of the formation, circulation and ventilation of Eastern North Atlantic Central Water. Progress in Oceanography 37, 167-192. doi: 10.1016/S0079-6611(96)00008-0.

1187 Pollard, R.T., Read, J.F., Holliday, N.P., Leach, H., 2004. Water masses and circulation pathways through the Iceland Basin during Vivaldi 1996. Journal of Geophysical Research 109, C04004. doi: 10.1029/2003JC002067.

Read, J.F., 2000. CONVEX-91: water masses and circulation of the Northeast Atlantic subpolar gyre. Progress in Oceanography 48, 4, 461-510. doi: 10.1016/S0079-6611(01)00011-8.

Reid, J.L., 1979. On the contribution of the Mediterranean Sea outflow to the NorwegianGreenland Sea. Deep Sea Research Part A. Oceanographic Research Papers 26, 11, 1199-1223. doi: 10.1016/0198-0149(79)90064-5.

Rhein, M., Fischer, J., Smethie, W.M., Smythe-Wright, D., Weiss, R.F., Mertens, C., Min, D.-H., Fleischmann, U., Putzka, A., 2002. Labrador Sea Water: Pathways, and formation rates. Journal of Physical Oceanography 32, 648-665. doi: 10.1175/15200485(2002)0322.0.CO;2. 
1199 Ross, C.K., 1984. Temperature-salinity characteristics of the "overflow" water in Denmark Strait during “OVERFLOW'73.” Rapp. PV Reun. Cons. Int. Explor. Mer 185, 111-119.

1201 Rudels, B., Fahrbach, E., Meincke, J., Budéus, G., Eriksson, P., 2002. The East Greenland Current and its contribution to the Denmark Strait overflow. ICES Journal of Marine Science: Journal du Conseil 59, 6, 1133-1154. doi: 10.1006/jmsc.2002.1284.

Sarafanov, A., 2009. On the effect of the North Atlantic Oscillation on temperature and salinity of 1205 the subpolar North Atlantic intermediate and deep waters. ICES Journal of Marine Science 66, 7, 1448-1454. doi: 10.1093/icesjms/fsp094.

1207 Sarafanov, A., Falina, A., Mercier, H., Sokov, A., Lherminier, P., Gourcuff, C., Gladyshev, S., Gaillard, F., Daniault, N., 2012. Mean full-depth summer circulation and transports at the northern periphery of the Atlantic Ocean in the 2000s. Journal of Geophysical Research 117, C1, C01014. doi: 10.1029/2011JC007572.

1211 Sarafanov, A., Mercier, H., Falina, A., Sokov, A., Lherminier, P., 2010. Cessation and partial reversal of deep water freshening in the northern North Atlantic: observation-based estimates and attribution. Tellus A 62, 1, 80-90. doi: 10.1111/j.1600-0870.2009.00418.x.

1214 Saunders, P.M., 1986. The accuracy of measurements of salinity, oxygen and temperature in the deep ocean. Journal of Physical Oceanography 16, 189-195. doi: 10.1175/15200485(1986)016<0189:TAOMOS>2.0.CO;2.

1217 Saunders, P.M., 1996. The Flux of Dense Cold Overflow Water Southeast of Iceland. Journal of Physical Oceanography 26, 1 , 85-95. doi: $10.1175 / 1520$ 0485(1996)026<0085:TFODCO>2.0.CO;2.

Saunders, P.M., 2001. The dense northern overflows, in: Ocean Circulation and Climate, Edited by G. Siedler, J. Church, and J. Gould. Academic, New York, pp. 401-417.

Schmitz Jr, W., 1996. On the World Ocean Circulation: Volume I: some global features/North 
1227 Schott, F.A., Brandt, P., 2007. Circulation and deep water export of the subpolar North Atlantic during the 1990s, in Ocean Circulation: Mechanisms and Impacts. Geophys. Monogr. Ser., vol. 173, edited by A. Schmittner, J. Chiang, and S. Hemmings, pp. 91-118, AGU, Washington, D.C., doi: 10.1029/173GM08.

1231 Stoll, M.H.C., van Aken, H.M., de Baar, H.J.W., Kraak, M., 1996. Carbon dioxide characteristics of water masses in the northern North Atlantic Ocean. Marine Chemistry 55, 3-4, 217-232. doi: 10.1016/S0304-4203(96)00058-8.

Stramma, L., Kieke, D., Rhein, M., Schott, F., Yashayaev, I., Koltermann, K.P., 2004. Deep water changes at the western boundary of the subpolar North Atlantic during 1996 to 2001. Deep Sea Research Part I: Oceanographic Research Papers 51, 8, 1033-1056. doi: 10.1016/j.dsr.2004.04.001.

Sutherland, D.A., Pickart, R.S., 2008. The East Greenland Coastal Current: Structure, variability, and forcing. Progress in Oceanography 78, 58-77. doi:10.1016/j.pocean.2007.09.006.

Takahashi, T., Broecker, W.S., Langer, S., 1985. Redfield ratio based on chemical data from isopycnal surfaces. Journal of Geophysical Research 90, C4, 6907-6924. doi: 10.1029/JC090iC04p06907.

Talley, L.D., McCartney, M.S., 1982. Distribution and circulation of Labrador Sea Water. Journal of Physical Oceanography 12, 1189-1205. doi: 10.1175/15200485(1982)012<1189:DACOLS>2.0.CO;2.

Tanhua, T., Olsson, K.A., Jeansson, E., 2005. Formation of Denmark Strait overflow water and its hydro-chemical composition. Journal of Marine Systems 57, 3, 264-288. doi: 10.1016/j.jmarsys.2005.05.003.

1249 Tanhua, T., Olsson, K.A., Jeansson, E., 2008. Tracer evidence of the origin and variability of

1253 Thierry, V., De Boisséson, E., Mercier, H., 2008. Interannual variability of the Subpolar Mode 
1256 Thompson, R.O., Edwards, R.J., 1981. Mixing and water-mass formation in the Australian 1257 Subantarctic. Journal of Physical Oceanography 11, 10, 1399-1406. doi: 10.1175/15200485(1981)011<1399:MAWMFI>2.0.CO;2.

1259 Tomczak, M., 1981. A multi-parameter extension of temperature/salinity diagram techniques for the analysis of non-isopycnal mixing. Progress in Oceanography 10, 3, 147-171. doi: 10.1016/0079-6611(81)90010-0.

Tomczak, M., 1999. Some historical, theoretical and applied aspects of quantitative water mass analysis. Journal of Marine Research 57, 2, 275-303. doi: 10.1357/002224099321618227.

Tomczak, M., Large, D.G., 1989. Optimum multiparameter analysis of mixing in the thermocline of the eastern Indian Ocean. Journal of Geophysical Research 94, C11, 16141-16149. doi: 10.1029/JC094iC11p16141.

1267 Tsuchiya, M., Talley, L.D., McCartney, M.S., 1992. An eastern Atlantic section from Iceland

van Aken, H.M., 2000. The hydrography of the mid-latitude northeast Atlantic Ocean I: The deep water masses. Deep Sea Research Part I: Oceanographic Research Papers 47, 5, 757788. doi: 10.1016/S0967-0637(99)00092-8.

van Aken, H.M., Becker, G., 1996. Hydrography and through-flow in the north-eastern North Atlantic Ocean: the NANSEN project. Progress in Oceanography 38, 4, 297-346. doi: 10.1016/S0079-6611(97)00005-0.

van Aken, H.M., de Boer, C.J., 1995. On the synoptic hydrography of intermediate and deep water masses in the Iceland Basin. Deep Sea Research Part I: Oceanographic Research Papers 42, 2, 165-189. doi: 10.1016/0967-0637(94)00042-Q.

van Aken, H.M., de Jong, M.F., 2012. Hydrographic variability of Denmark Strait Overflow Water near Cape Farewell with multi-decadal to weekly time scales. Deep Sea Research Part I: Oceanographic Research Papers 66, 41-50. doi: 10.1016/j.dsr.2012.04.004.

von Appen, W.-J., Koszalka, I.M., Pickart, R.S., Haine, T.W.N., Mastropole, D., Magaldi, M.G., Valdimarsson, H., Girton, J., Jochumsen, K., Krahmann, G., 2014. The East Greenland Spill Jet as an important component of the Atlantic Meridional Overturning Circulation. 
Deep Sea Research Part I: Oceanographic Research Papers 92, 75-84. doi: 10.1016/j. dsr.2014.06.002.

1287 Willebrand, J., Barnier, B., Böning, C., Dieterich, C., Killworth, P.D., Le Provost, C., Jia, Y., Molines, J.-M., New, A.L., 2001. Circulation characteristics in three eddy-permitting models of the North Atlantic. Progress in Oceanography 48, 123-161. doi: 10.1016/S00796611(01)00003-9.

1291 Wüst, G., Defant, A., 1936. Atlas zur Schichtung und Zirkulation des Atlantischen Ozeans. Wissenschaftliche Ergebnisse: Deutsche Atlantische Expedition auf dem Forschungs- und Vermessungsschiff "Meteor" 1925-1927 6, Atlas, 103.

1294 Xu, X., Hurlburt, H.E., Schmitz Jr., W.J., Zantopp, R., Fischer, J., Hogan, P.J., 2013. On the currents and transports connected with the atlantic meridional overturning circulation in the subpolar North Atlantic. Journal of Geophysical Research 118, 502-516. doi: 10.1002/jgrc.20065.

Xu, X., Schmitz Jr, W.J., Hurlburt, H.E., Hogan, P.J., Chassignet, E.P., 2010. Transport of Nordic Seas overflow water into and within the Irminger Sea: An eddy-resolving simulation and observations. Journal of Geophysical Research 115, C12048. doi: 10.1029/2010JC006351. Oceanography 73, 3, 242-276. doi: 10.1016/j.pocean.2007.04.015.

1303 Yashayaev, I., Bersch, M., van Aken, H.M., 2007. Spreading of the Labrador Sea Water to the 1304 Irminger and Iceland basins. Geophysical Research Letters 34, 10, L10602. doi: 10.1029/2006GL028999.

Yashayaev, I., Dickson, R.R., 2008. Transformation and fate of overflows in the Northern North Atlantic, in: Dickson, R.R., Jens, M., Rhines, P. (Eds.), Arctic-Subarctic Ocean Fluxes:

1310 Yashayaev, I., Holliday, N.P., Bersch, M., van Aken, H.M., 2008. The History of the Labrador Sea Water: Production, Spreading, Transformation and Loss, in: Dickson, R.R., Jens, M., Rhines, P. (Eds.), Arctic-Subarctic Ocean Fluxes: Defining the Role of the Northern Seas in 
1313 Climate. Springer, Science+Business Media B.V., P.O. Box 17, AA Dordrecht, The $1314 \quad$ Netherlands, pp. 569-612. 


\section{Figure captions}

Figure 1: Location of the $4 x$ and OVIDE hydrographic stations plotted on bathymetry $(500 \mathrm{~m}$ intervals). The North Atlantic circulation scheme, the major topographical features of the Subpolar North Atlantic, as well as the main water masses are also shown: East Greenland Current (EGC), West Greenland Current (WGC), Labrador Current (LC), Deep Western Boundary Current (DWBC), North Atlantic Current (NAC), Denmark Strait Overflow Water (DSOW), Iceland-Scotland Overflow Water (ISOW), Labrador Sea Water (LSW), Mediterranean Water (MW), North East Atlantic Deep Water (NEADW), Charlie-Gibbs Fracture Zone (CGFZ), Bight Fracture Zone (BFZ), Mid-Atlantic Ridge (M.A.R.) and Iberian Abyssal Plain (I.A.P.). Schematic diagram of the largescale circulation compiled from Schmitz and McCartney (1993), Dengler et al. (2006), Schott and Brandt (2007, Plate 1), Sutherland and Pickart (2008, Fig. 16), Lherminier et al. (2010, Fig. 1b) and Sarafanov et al. (2012).

Figure 2: Mean (a) potential temperature $(\theta)$, (b) salinity, (c) oxygen, (d) nitrate, (e) silicate and (f) phosphate along the OVIDE section, from the Iberian Peninsula (right) to Greenland (left).

Figure 3: (A) Potential temperature $(\theta) /$ Salinity (S)-diagram including the Source Water Types (Table 2) used in the analysis and (B) zoomed for bottom waters. The mixing figures are shown in the (C) legend (see Table 2 for the acronyms of the source water types). The isopycnals referenced in the chapter are also plotted, i.e., $\sigma_{1}=32.15$ and $\sigma_{1}=32.42$ (where is $\sigma_{1}$ potential density referenced to $1000 \mathrm{dbar})$.

Figure 4: Water mass distributions of the mean result for the OVIDE sections (2002-2010), from the Iberian Peninsula (right) to Greenland (left). The water mass contributions are expressed on a per unit basis (see Table 2 for the acronyms of the source water types). The dashed horizontal lines represent isopycnals: $\sigma_{1}=32.15$, which marks the limit between the upper and lower limb of the Atlantic Meridional Overturning Circulation (plot a); and $\sigma_{1}=32.42$ (very similar to $\sigma_{0}=27.8$ ), which marks the lower limit of Labrador Sea Water (LSW) on the classic works (plot e) and 
approximately crosses the potential temperature/salinity definition of the source water type for LSW (Fig. 3a). $\sigma_{1}=32.42$ has the advantage of not varying rapidly in the eastern half of the sections.

Figure 5: Water mass distributions along the WOCE A25 sections, from 1997 (4x section, upper plots) to 2010 (OVIDE section, lower plots), from the Iberian Peninsula (right) to Greenland (left). The water mass contributions are expressed on a per unit basis. Note that SPMW = IrSPMW + IcSPMW. The dashed white line on the DSOW plots represents the limit of the PIW contributions (5 $\%$ isoline) (see Table 2 for the acronyms of the source water types).

Figure 6: Net water mass volume transports perpendicular to the OVIDE section for the mean result of the period (2002-2010). Transports (in Sv; $1 \mathrm{~Sv}=10^{6} \mathrm{~m}^{3} \mathrm{~s}^{-1}$ ) are positive northwards. Note that Central refers to Central Waters (see Table 2 for the acronyms of the source water types).

Figure 7: Schematic diagram of the water mass circulation, transformation and transports in the North Atlantic Subpolar Gyre, based on a two-layer box model in between the OVIDE sections and the Greenland-Iceland-Scotland sills (GISS). The transports (in Sv; $1 \mathrm{~Sv}=10^{6} \mathrm{~m}^{3} \mathrm{~s}^{-1}$ ) at the southern boundary are the mean transports across the OVIDE sections as obtained in the present study. The transports at the northern boundary (GISS) are defined as explained in section 5 . The boundary between the western (East North Atlantic (ENA) Basin) and eastern (Irminger Basin) boxes is the Reykjanes Ridge (RR). RR is closed (open) for the deep (upper-ocean and mid-depth) circulation. The diapycnal volume fluxes (crossed and point circles) and the transports across the RR are inferred from the condition of volume conservation. The uncertainties are shown in grey. Note that $\mathrm{CW}$ accounts for Central Waters and AW for Atlantic waters (see Table 2 for the acronyms of the source water types); I.P. for Iberian Peninsula.

Figure A3.1: Total residual from the extended Optimum MultiParameter (eOMP) analysis (a) and individual residuals from each eOMP equation: (b) potential temperature $\left(\theta\right.$, in $\left.{ }^{\circ} \mathrm{C}\right)$ and salinity $(S)$; 
(c) silicate $\left(\mathrm{SiO}_{2}\right)$ and nitrate $\left(\mathrm{NO}_{3}\right)$ (both in $\left.\mu \mathrm{mol} \mathrm{kg}{ }^{-1}\right)$; and (d) phosphate $\left(\mathrm{PO}_{4}\right)$ and oxygen $\left(\mathrm{O}_{2}\right)$ (both in $\mu \mathrm{mol} \mathrm{kg}{ }^{-1}$ ). 
Figure 1

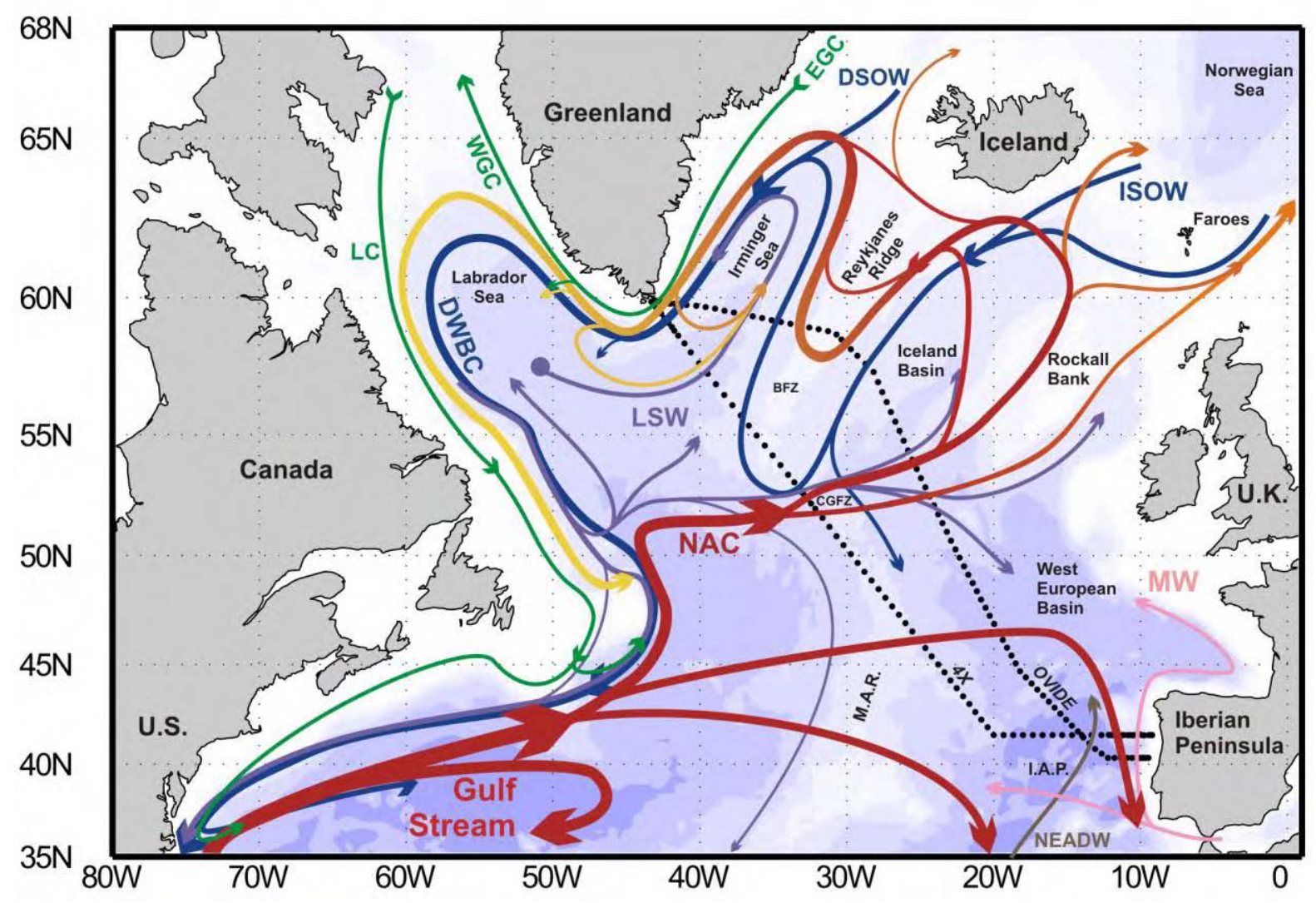


Figure 2
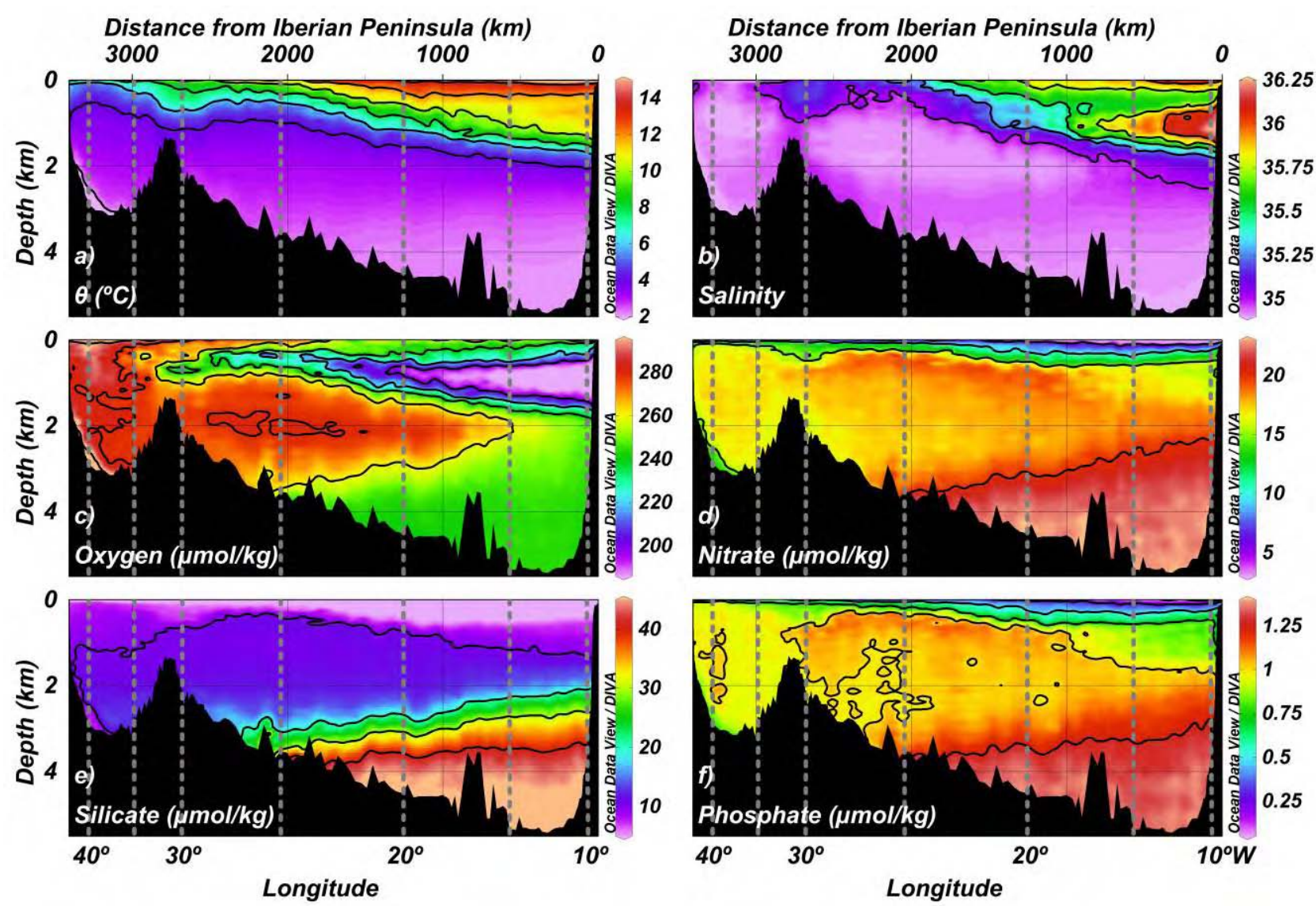
Figure 3

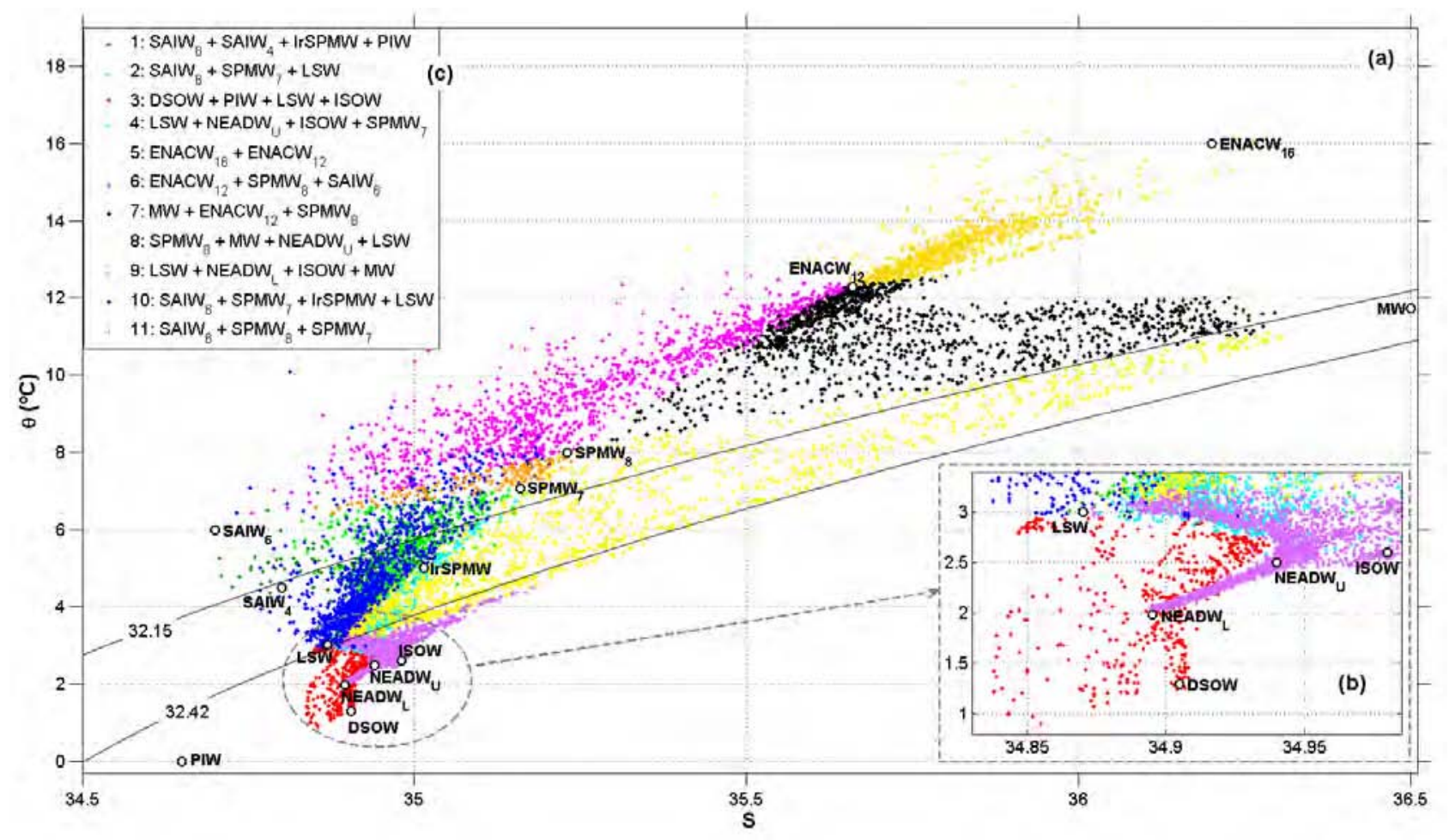


Figure 4

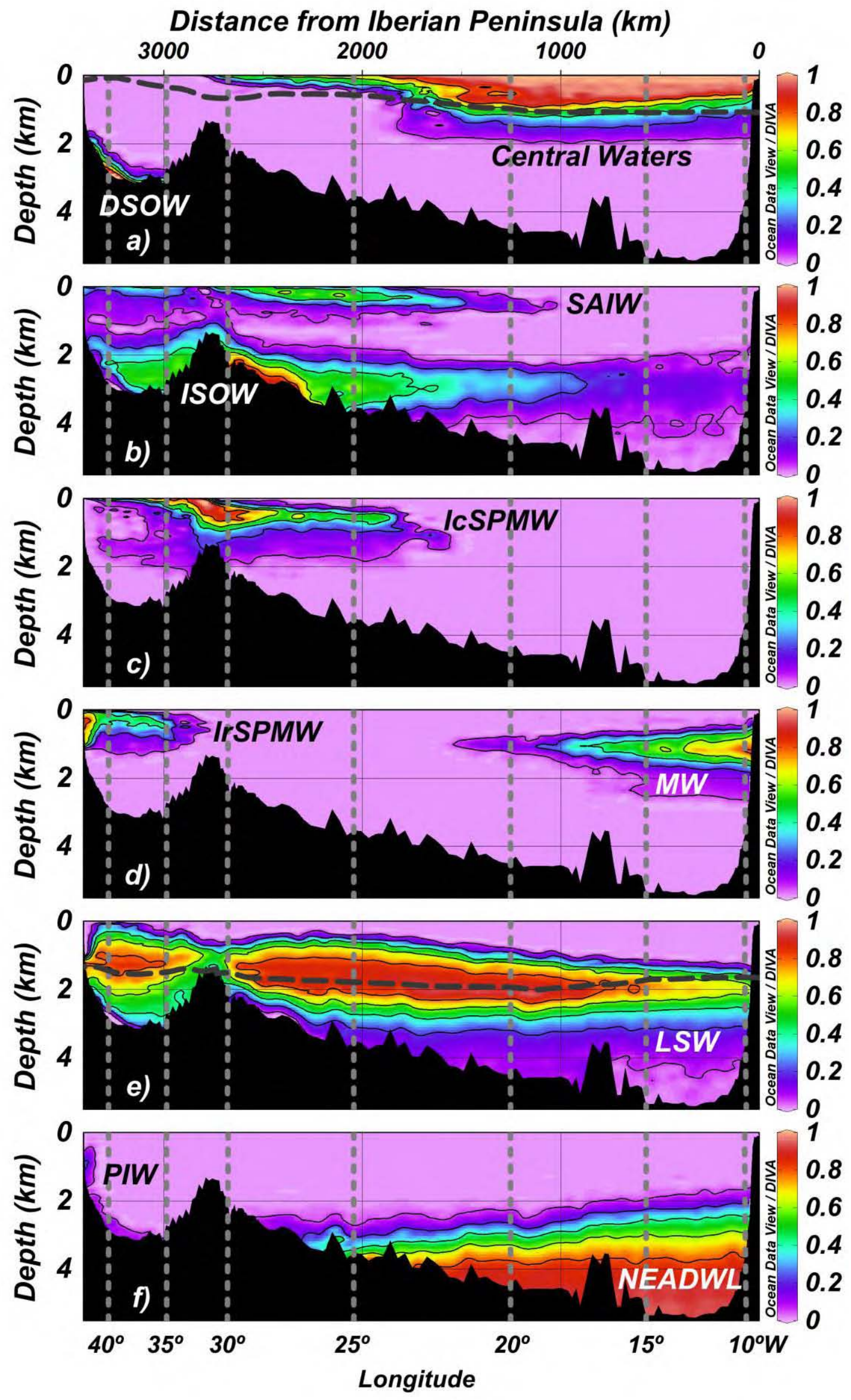


Figure 5
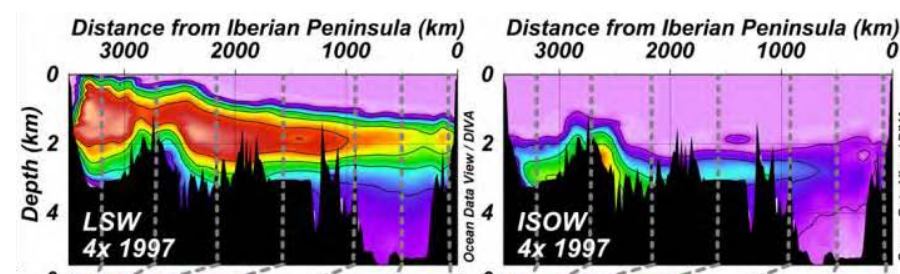

Distance from Iberian Peninsula (km) Dist. from Iberian Peninsula (km)

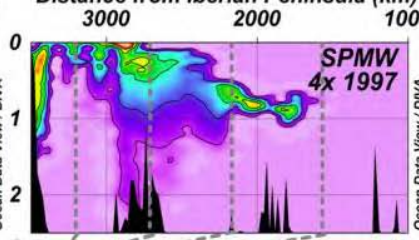
$\begin{array}{llll} & 3450 & 3150 \quad 3000\end{array}$
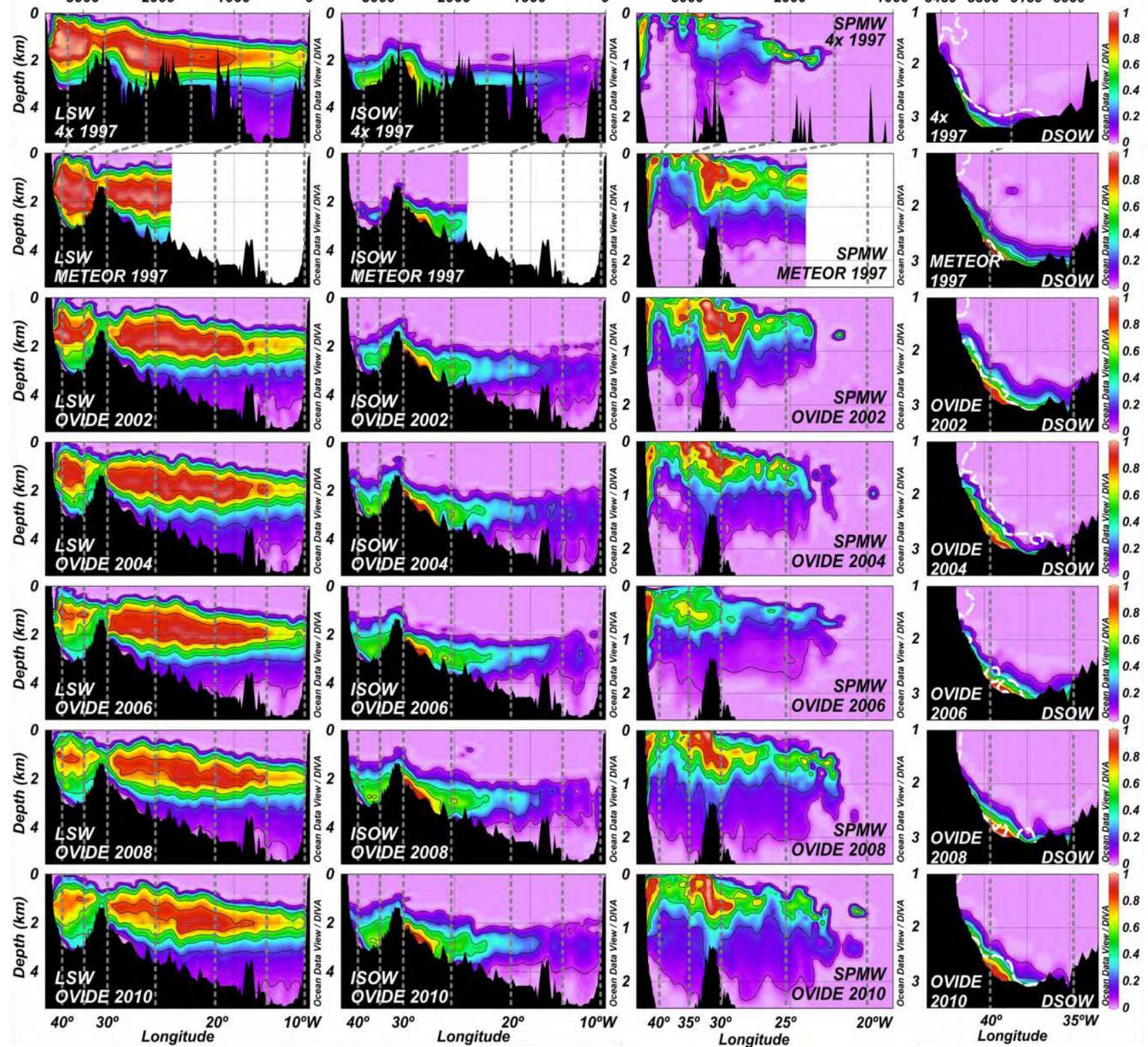
Figure 6

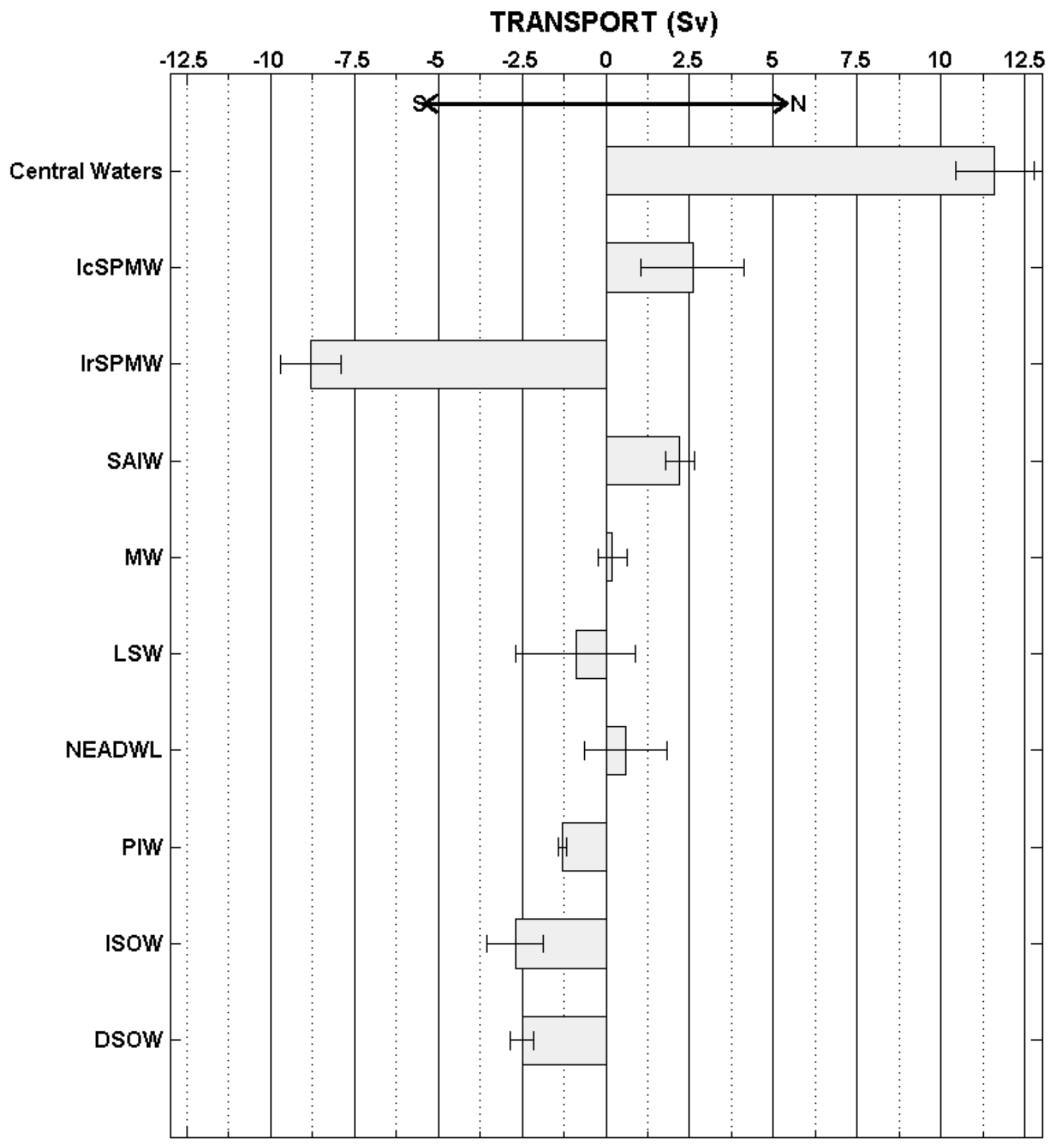


Figure 7
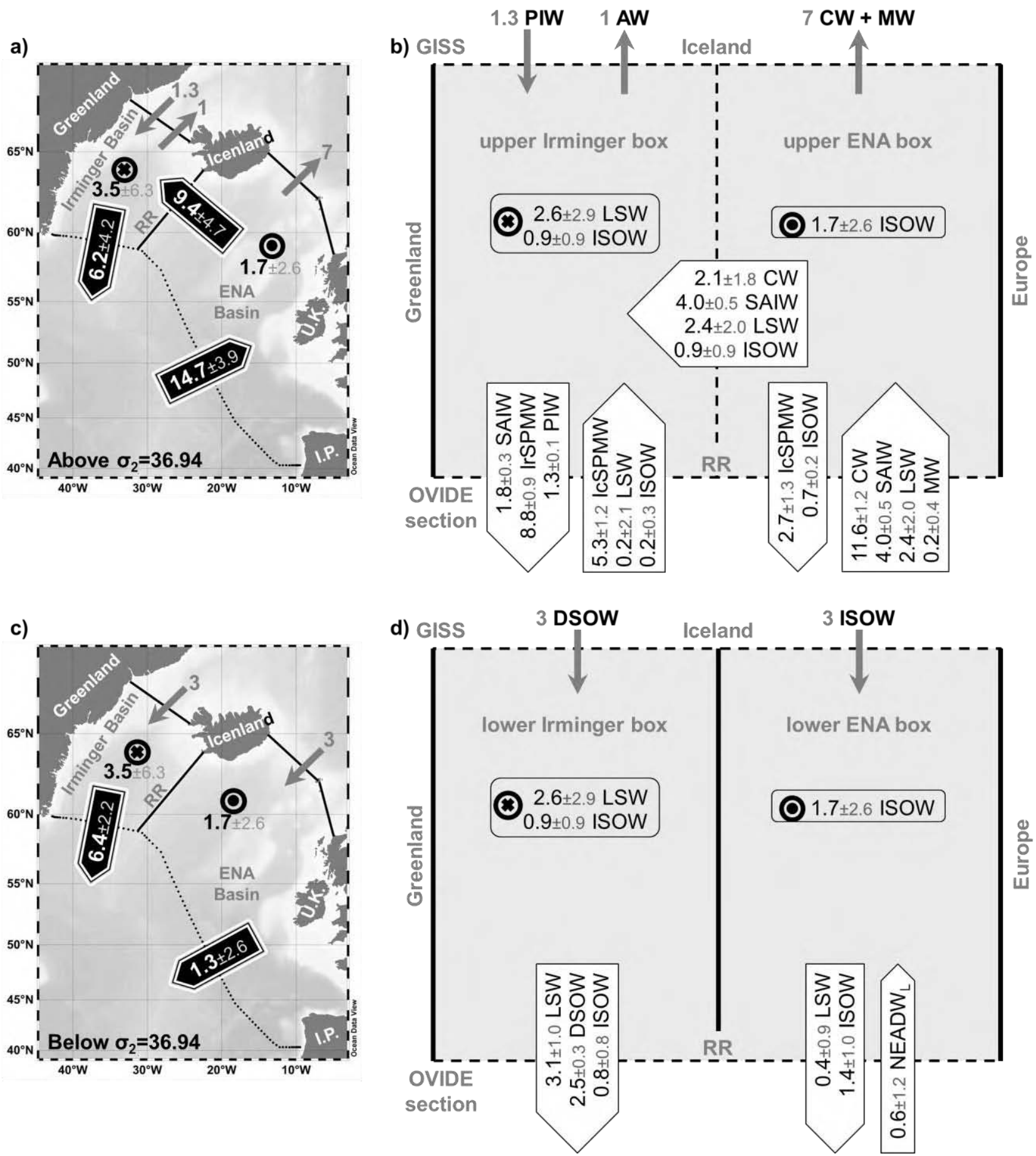
Figure A3.1
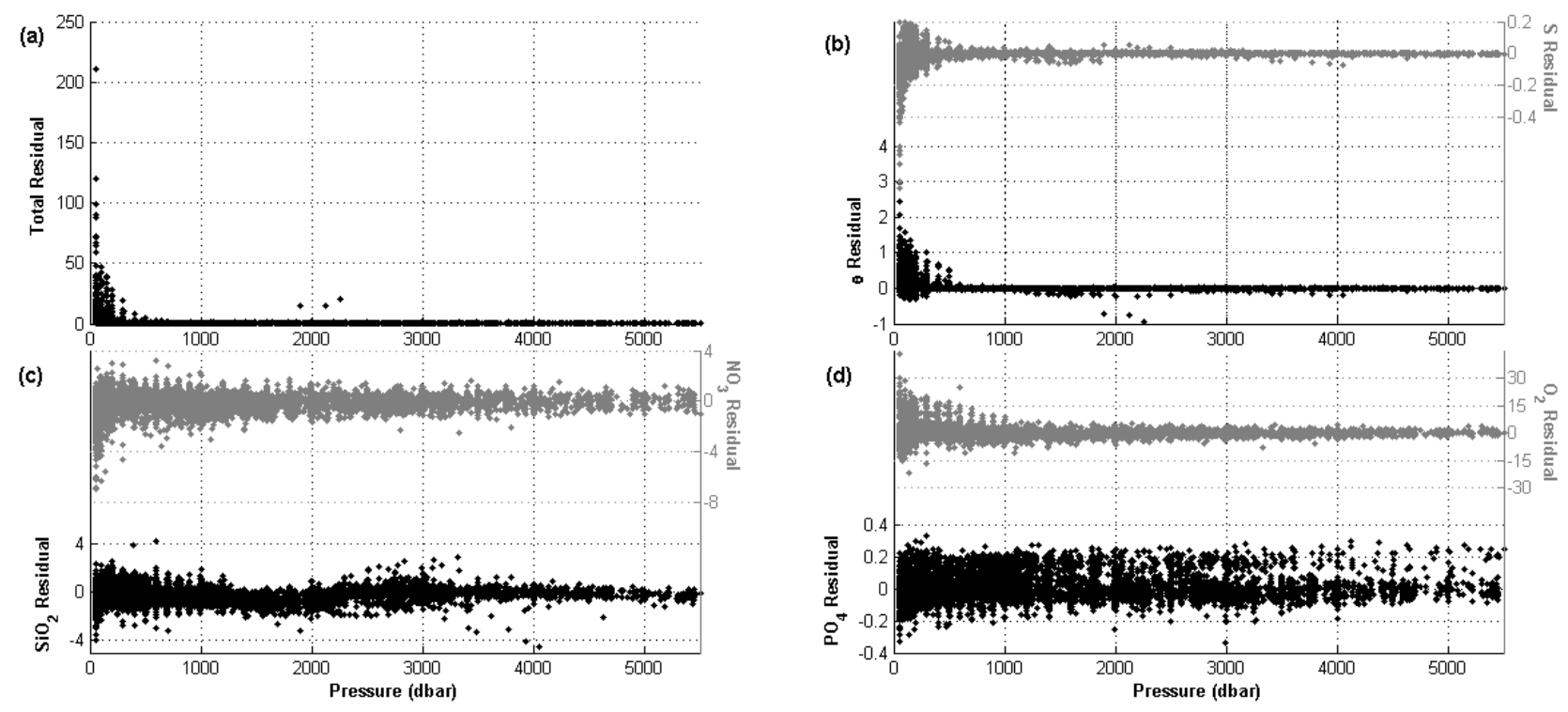
Table 1: Hydrographic cruises.

\begin{tabular}{llll}
\hline Cruise Name & Month/Year & Vessel & Reference \\
\hline METEOR 1997 & $08-09 / 1997$ & R/V Meteor & Rhein et al. (2002) \\
4x 1997 & $08-09 / 1997$ & R/V Discovery & Álvarez et al. (2002) \\
OVIDE 2002 & $06-07 / 2002$ & N/O Thalassa & Lherminier et al. (2007) \\
OVIDE 2004 & $06-07 / 2004$ & N/O Thalassa & Lherminier et al. (2010) \\
OVIDE 2006 & $05-06 / 2006$ & R/V Maria S. Merian & Gourcuff et al. (2011) \\
OVIDE 2008 & $06-07 / 2008$ & N/O Thalassa & Mercier et al. (2013) \\
OVIDE 2010 & $06-07 / 2010$ & N/O Thalassa & Mercier et al. (2013) \\
\hline
\end{tabular}


Table 2: Main properties of each of the Source Water Types (SWTs) considered in the study with their corresponding standard deviation. The weights of each equation are also given, together with the square of correlation coefficients $\left(r^{2}\right)$ between the observed and estimated properties, the

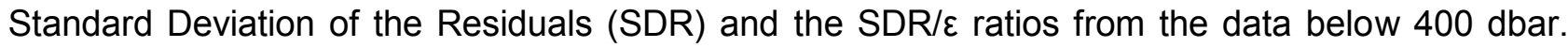
The $\varepsilon$ used to compute the $S D R / \varepsilon$ ratios are the accuracies of the measured properties listed in Appendix A2. The last column accounts for the uncertainties in the SWTs contributions. Values expressed on a per one basis.

\begin{tabular}{|c|c|c|c|c|c|c|c|}
\hline & $\begin{array}{l}\text { Potential } \\
\text { temperature } \\
\left(\theta^{S W T}\right)\end{array}$ & Salinity $\left(S^{S W T}\right)$ & $\begin{array}{l}\text { Silicate } \\
\left(\mathrm{SiO}_{2}^{0} S W T\right)\end{array}$ & $\begin{array}{l}\text { Nitrate } \\
\left(\mathrm{NO}_{3}^{0 S W T}\right)\end{array}$ & $\begin{array}{l}\text { Phosphate } \\
\left(\mathrm{PO}_{4}^{0 S W T}\right)\end{array}$ & $\begin{array}{l}\text { Oxygen } \\
\left(O_{2}^{0 S W T}\right)\end{array}$ & \multirow[t]{2}{*}{ Uncertainty } \\
\hline & \multicolumn{2}{|l|}{${ }^{\circ} \mathrm{C}$} & \multicolumn{4}{|l|}{$\mu \mathrm{mol} \mathrm{kg}{ }^{-1}$} & \\
\hline $\mathrm{ENACW}_{16}$ & $16.00 \pm 0.13$ & $36.20 \pm 0.02$ & $0.85 \pm 0.12$ & $0.00 \pm 0.16$ & $0.00 \pm 0.01$ & $241 \pm 7$ & 0.04 \\
\hline ENACW $_{12}$ & $12.30 \pm 0.18$ & $35.66 \pm 0.03$ & $1.6 \pm 0.8$ & $7 \pm 1$ & $0.31 \pm 0.07$ & $251 \pm 8$ & 0.04 \\
\hline MW & $11.7 \pm 0.2$ & $36.500 \pm 0.011$ & $4.88 \pm 0.15$ & $10.9 \pm 0.2$ & $0.70 \pm 0.03$ & $210 \pm 8$ & 0.015 \\
\hline SAIW $_{6}$ & $6.0 \pm 0.2$ & $34.70 \pm 0.03$ & $6.3 \pm 2.2$ & $13 \pm 1$ & $0.86 \pm 0.07$ & $287 \pm 9$ & 0.04 \\
\hline $\mathrm{SAIW}_{4}$ & $4.5 \pm 0.2$ & $34.80 \pm 0.03$ & $1.4 \pm 2.2$ & $0 \pm 1$ & $0.05 \pm 0.07$ & $290 \pm 9$ & 0.05 \\
\hline $\mathrm{SPMW}_{8}$ & $8.00 \pm 0.11$ & $35.230 \pm 0.016$ & $3.2 \pm 2.2$ & $11 \pm 1$ & $0.68 \pm 0.01$ & $289 \pm 6$ & 0.07 \\
\hline $\mathrm{SPMW}_{7}$ & $7.07 \pm 0.07$ & $35.160 \pm 0.006$ & $5.38 \pm 0.16$ & $13.70 \pm 0.16$ & $1.06 \pm 0.01$ & $280 \pm 9$ & 0.08 \\
\hline IrSPMW & $5.00 \pm 0.02$ & $35.014 \pm 0.013$ & $7.1 \pm 0.4$ & $15.0 \pm 0.4$ & $0.98 \pm 0.02$ & $300 \pm 9$ & 0.13 \\
\hline LSW & $3.00 \pm 0.19$ & $34.87 \pm 0.02$ & $10.0 \pm 0.8$ & $16.5 \pm 0.8$ & $1.05 \pm 0.12$ & $287 \pm 10$ & 0.10 \\
\hline ISOW & $2.60 \pm 0.08$ & $34.980 \pm 0.003$ & $10 \pm 1$ & $15.5 \pm 0.6$ & $1.20 \pm 0.04$ & $289 \pm 10$ & 0.08 \\
\hline DSOW & $1.30 \pm 0.06$ & $34.905 \pm 0.006$ & $7.8 \pm 0.5$ & $14.1 \pm 0.8$ & $1.10 \pm 0.06$ & $309 \pm 10$ & 0.05 \\
\hline PIW & $0.0 \pm 0.2$ & $34.65 \pm 0.03$ & $8.4 \pm 2.2$ & $9 \pm 1$ & $0.25 \pm 0.07$ & $310 \pm 11$ & 0.06 \\
\hline $\mathrm{NEADW}_{\mathrm{U}}$ & $2.50 \pm 0.08$ & $34.940 \pm 0.007$ & $29.2 \pm 0.6$ & $19.2 \pm 0.6$ & $1.32 \pm 0.05$ & $269 \pm 10$ & - \\
\hline NEADW ${ }_{\mathrm{L}}$ & $1.98 \pm 0.03$ & $34.895 \pm 0.003$ & $48.0 \pm 0.4$ & $22.6 \pm 0.5$ & $1.50 \pm 0.04$ & $252 \pm 10$ & 0.02 \\
\hline Weights & 20 & 10 & 2 & $3^{*}$ & $2^{*}$ & 2 & \\
\hline$r^{2}$ & 0.9991 & 0.9891 & 0.9975 & 0.9784 & 0.9477 & 0.9926 & \\
\hline SDR & 0.02 & 0.006 & 0.5 & 0.5 & 0.07 & 2 & \\
\hline $\mathrm{SDR} / \varepsilon$ & 2 & 1 & 2 & 3 & 3 & 2 & \\
\hline
\end{tabular}

* The weights for $\mathrm{NO}$ and $\mathrm{PO}$ are the same as for $\mathrm{NO}_{3}^{0}$ and $\mathrm{PO}_{4}^{0}$, respectively.

** $\mathrm{O}_{2}$ and nutrients represent preformed values; note that $\mathrm{O}_{2}$ values are close to saturation and nutrient values are low.

${ }^{* * *} \mathrm{ENACW}_{16}$ and $\mathrm{ENACW}_{12}=$ Eastern North Atlantic Central Waters; MW = Mediterranean Water; SAIW $_{6}$ and SAIW $4=$ Subarctic Intermediate Waters; SPMW 8 and SPMW $7=$ Subpolar Mode Waters of the Iceland Basin and IrPMW = of the Irminger Basin; LSW = Labrador Sea Water; ISOW = Iceland-Scotland Overflow Water; DSOW = Denmark Strait Overflow Waters; PIW = Polar Intermediate Water; and NEADW $\mathrm{N}_{\mathrm{U}}=$ North East Atlantic Deep Water upper and NEADW $\mathrm{L}=$ lower.

**** NEADW $W_{U}$ has no uncertainty value since it is considered as a composed SWT (MW + LSW +

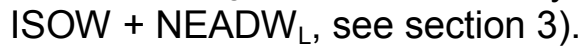

